\title{
Equivalent roughness height for plane bed under oscillatory flow
}

\author{
Benoît Camenen* Magnus Larson`, and Atilla Bayram;
}

November 20, 2008

\begin{abstract}
A new relationship between the roughness height and the main hydrodynamic and sediment parameters for plane beds under oscillatory conditions is presented. In order to derive such a relationship, a large data base encompassing plane bed experiments was compiled from previous investigations and analyzed. Different methods to estimate the roughness height were investigated. Comparisons between the data and different existing predictive formulas for the bed roughness obtained from the literature were also performed. A relationship involving the grain size and Shields parameter only, which is commonly proposed, appeared to be insufficient to characterize the roughness. The roughness height was also found to be a function of the sediment density and the settling velocity. A critical Shields parameter was identified up to which the effective roughness ratio is proportional to the Shields parameter only. The new empirical equation developed in this study provides the highest predictive skill for all conditions investigated.
\end{abstract}

\section{Keywords}

Roughness height, friction factor, oscillatory flow, plane bed, sheet flow, experimental data, predictive formula

\footnotetext{
*Cemagref, HHLY, 3 bis quai Chauveau, CP 220 F-69336 Lyon cedex 09, FRANCE Tel: +33 (0)4 722086 07, Email: camenen@lyon.cemagref.fr

${ }^{\dagger}$ Dept. of Water Resources Eng., Lund University, Box 118, S-221 00 Lund, SWEDEN, E-mail: magnus.larson@tvrl.lth.se

${ }^{\ddagger}$ Halcrow, 22 Cortlandt St. 31st floor, NY 10007, U.S.A. E-mail: abayram@halcrow.com
} 


\section{Introduction}

Accurate sediment transport rate predictions in coastal areas closely depend on estimates of the resistance to oscillating flows on the sea bottom. A roughness height is typically employed to characterize the resistance properties of the bottom. Although the roughness height remains quite difficult to determine, it is a fundamental parameter for calculating sediment transport rates. Numerical models to compute sediment transport rate in river or coastal environments often employ relationships which depend on the Shields parameter. The bed roughness is an important input quantity in the Shields parameter, and it is usually unknown even for the simpler case of steady current conditions.

In general, for dimensional reasons, the bed roughness height of a flat and fixed bed is given in terms of the Nikuradse roughness height $\left(k_{s}\right)$. For flat beds, it is expected to be on the order of the median grain diameter or of some larger grain size percentiles ( $k_{s}=1$ to 5 times $d_{50}, d_{65}, d_{84}$, or $d_{90}$ according to the literature). However, the value of $k_{s}$ varies considerably depending on the configuration of the grains forming the roughness of the flow boundaries. At high Shields parameter values, the sediment moves along the bottom mainly in a layer denoted as sheet flow. The presence of a relatively thin sheet flow layer with high sediment concentration markedly affects the flow above it. One important aspect of the presence of a sheet flow layer is the increased roughness, compared to a situation without such a layer. Under sheet flow conditions, the roughness height may be several orders of magnitude larger than for a fixed bed. This is probably caused by the increased energy dissipation in the sheet flow layer due to interaction between individual sediment grains as well as between the sediment and the fluid. It is often assumed that the roughness height under sheet flow conditions is on the order of the layer thickness (Wilson 1987, Van Rijn 1993).

Wilson (1966) performed a series of tests in a pressurized conduit in order to obtain high shear stress values. Based on these results, he proposed a linear relationship between the relative roughness and the Shields parameter. Some more recent studies (Nnadi \& Wilson 1992, Sumer et al. 1996) confirm this relationship with the Shields parameter. However, all these experiments were performed for steady currents. Few experiments have been performed under oscillatory flow conditions, and mostly in the laboratory. Moreover, if the shear stress at the bottom (and thus the roughness height) can be easily estimated in the case of steady flows using energy slope measurements (Camenen et al., 2006), this estimation becomes more difficult in the case of oscillatory flows. An extensive laboratory data set was compiled in this study, allowing for a more comprehensive analysis of this difficulty. Five methods were compared to estimate the roughness height for oscillatory flows based on the velocity profiles, energy dissipation, momentum equation in the fluid/sediment mixture, sheet flow layer thickness, and bed-load sediment transport. Most of the existing methods are actually indirect as the bed shear stress is not directly measured but estimated from other parameters. Thus, some additional uncertainties exist based on the theoretical formulation to calculate the bed shear stress from these other parameters. Bayram et al. (2001) encountered the problem of finding reliable relationships to predict roughness height during sheet flow conditions in the surf zone when evaluating the predictive capability of available 
longshore sediment transport formulas against field data, which motivated the present study.

The term "equivalent" roughness height (or bed shear stress) is used here as it does not necessarily correspond to the real value but to the one obtained in a "clear water" model over a fixed bed to simulate the same flow discharge and hydraulic gradient as measured for the mobile bed situation. The analogy with an oscillating turbulent clear water flow over a fixed bed is assumed in order to use classical formulas for the friction coefficient such as the Jonsson (1966) formula. By definition, the equivalent bed shear stress is thus different as the real bed shear stress below a sheet flow layer.

Nielsen (1992) investigated the equivalent Nikuradse roughness of natural sand beds exposed to both steady and oscillatory flows. Based on data collected by Carstens et al. (1969) and Lofquist (1986), Nielsen showed that flat beds in oscillatory sheet flow (i.e., Shields parameter $\theta \geq 0.8$ ) generally exhibit roughness values on the order of 100 to 200 grain diameters. However, steady sheet flow data by Guy et al. (1966) produced roughness heights one order of magnitude smaller than the oscillatory flow. No satisfactory explanation has been given for this difference between the roughness values of sand beds under steady and oscillatory flows. Nielsen (1992) reasoned that the observed additional energy dissipation under waves due to percolation might explain the difference.

The objectives of the present study are twofold: (1) to complement the findings of Nielsen (1992) by analyzing additional high-quality available data sets; and (2) to propose a new predictive equivalent roughness height relationship for practical applications in sediment transport modeling in coastal areas, using various data sets from the literature. In developing an improved predictive relationship for the roughness height, several existing formulas were also compared with the compiled data set. The first part of the paper presents the previous studies ( $c f$. section 2), the different methods to estimate the roughness height ( $c f$. section 3.1), the data sets used in the present study ( $c f$. section 3.2), and the validation of the methods to estimate the roughness height (cf. section 3.3). The effects of the main parameters on the roughness height and the new predictive relationship are discussed in the second part ( $c f$. section 41).

\section{Roughness height relationships}

In general, the roughness height is assumed not to vary with time even for oscillating flows. Thus, all existing formulas yield an average value of the equivalent roughness height. Recently, some authors (Zala Flores \& Sleath, 1998; Nielsen, 2002) showed that it may vary around its mean value. However, the purpose of the present paper remains to improve the prediction of its mean value.

\subsection{Existing relationships}

In general, the main problem in bed roughness prediction under moving bed conditions is that the roughness height depends on the flow variables as well as on the sediment transport rate. In the literature, several existing relationships for equivalent 
roughness under sheet flow conditions have been proposed (see Table 1). Most of the existing formulas assume a relationship between an effective roughness ratio (ratio between the effective roughness height $k_{s}$ and a characteristic grain size $d$ ) and the Shields parameter based on the maximum shear stress $\theta$, according to,

$$
\frac{k_{s}}{d} \propto \theta^{\beta}
$$

where $\beta$ varies between 0.5 and 2 depending on the authors.

Table 1: Relationships to predict equivalent roughness for oscillatory sheet flow as they chronologically appeared in the literature.

$$
\begin{array}{lll}
\text { Grant \& Madsen (1982) } & \frac{k_{s}}{d_{50}}=160(s+0.5) \theta_{c r}\left(\sqrt{\frac{\theta^{\prime}}{\theta_{c r}}}-0.7\right)^{2} \\
\text { Wilson (1989) } & \frac{k_{s}}{d_{50}}=5 \theta \\
\text { Nielsen (1992, pp.154-155) } & \frac{k_{s}}{d_{50}}=70 \sqrt{\theta} \\
\text { Madsen et al. (1993) } & \frac{k_{s}}{d_{50}}=15 \\
\text { Xu \& Wright (1993) } & \frac{k_{s}}{d_{50}}=15 \theta \\
\text { Ribberink (1998) } & \frac{k_{s}}{d_{50}} & =\max [1,1+6(<\theta>-1)]
\end{array}
$$

In Table $1 d_{50}$ is the median diameter, and $\theta^{\prime}$ and $\theta$ are the skin and total Shields parameters, respectively. The Shields parameter is defined by,

$$
\theta=\frac{u_{*}{ }^{2}}{(s-1) g d_{50}}
$$

in which $u_{*}$ is the bed friction velocity, $s$ is the relative density of sediment grains $(s=$ $\rho_{s} / \rho$, where $\rho_{s}$ and $\rho$ are the density of sediment grains and fluid (water), respectively) and $g$ is the acceleration due to gravity.

The shear velocity can be calculated with the aid of the friction factor defined by Jonsson (1966),

$$
f_{w}=\frac{2 u_{*}{ }^{2}}{U_{w}{ }^{2}}=\frac{\tau_{w}}{1 / 2 \rho\left(A_{w} \omega\right)^{2}}
$$

where $U_{w}$ is the maximum bottom wave orbital velocity, $\tau_{w}$ the wave-induced bed shear stress, $A_{w}$ the amplitude of the near-bed wave orbital motion, and $\omega=2 \pi / T_{w}$ the angular frequency ( $T_{w}$ is the wave period). An assumption usually made for the coastal environment is that the rough turbulent regime is fully developed. Thus, the friction factor could be estimated by the formula suggested by Swart (1974), which 
is an explicit approximation to the implicit, semi-empirical formula given by Jonsson (1966):

$$
f_{w}=\exp \left[5.2\left(\frac{k_{s}}{A_{w}}\right)^{0.194}-5.98\right]
$$

Jonsson (1980) suggested an upper limit of 0.3 for the value of $f_{w}$. The skin shear stress is computed following the presented method and assuming that $k_{s}=2 d_{50}$. The choice of $k_{s}=2 d_{50}$ is based on a previous study for steady flows (Camenen et al., 2006). It corresponds to a mean value for the lower regime where the sediment transport does not affect the roughness height.

\subsection{Acceleration effects on the roughness height}

Zala Flores \& Sleath (1998) were the first who observed acceleration effects on the instantaneous velocity profile, and thus on the instantaneous shear stress. Their measurements show some influence of pressure gradient and inertia forces for large shear stresses where a type of plug flow is observed. They defined the parameter $S$ representing the ratio of inertia to gravity forces acting on individual grains to characterize this phenomena:

$$
S=\frac{U_{w} \omega}{(s-1) g}
$$

From the authors' point of view, the Shields parameter better characterizes the ratio of inertia to gravity forces. Also, the model proposed by Zala Flores \& Sleath links the ratio $\delta_{s} /\left(A_{w} f_{w}\right)$ to $S$ which directly leads to the Shields parameter for a linear case. For $S>0.2$, they observed a phase lead of the fundamental component of the velocity which varies depending on the relative rates of erosion and deposition of the sediments. This confirms the importance of the settling velocity and density of the sediments on the roughness height. Their measurements showed that the velocity profiles are different during the acceleration phase and the deceleration phase, which may induce a net sediment transport.

Nielsen (2002) showed that the acceleration asymmetry enhances the bed shear stress. He proposed to use a model for the skin shear stress that generates stronger shear stresses under the more abruptly accelerated part of the instantaneous free-stream velocity,

$$
\begin{aligned}
\theta_{w}(t) & =\frac{0.5 f_{w}}{(s-1) g d_{50}}\left|f\left(u_{w}(t), \varphi_{t}\right)\right| f\left(u_{w}(t), \varphi_{t}\right) \\
f\left(u_{w}(t), \varphi_{t}\right) & =\cos \varphi_{t} u_{w}(t)+\sin \varphi_{t} \frac{u_{w}\left(t+\delta_{t}\right)-u_{w}\left(t+\delta_{t}\right)}{2 \omega \delta_{t}}
\end{aligned}
$$

where the friction coefficient $f_{w}$ is calculated using the skin roughness height $\left(k_{s} \approx\right.$ $\left.2 d_{50}\right), \varphi_{t}$ is the phase shift between free-stream velocity and bed shear stress at the peak frequency (Nielsen found $\varphi_{t} \approx 37.5^{\circ}$ ), and $\delta_{t}$ is the time step (cf. Eq. 7 with $n=0$ in Nielsen, 2002, where $n \in[0 ; 1]$ is an interpolation parameter).

Camenen and Larson (2007a) proposed a simple model which increases the friction coefficient (previously assumed constant over a wave period) for accelerated flow and 
decreases it for decelerated flow. The mean Shields parameters in the onshore $\left(\theta_{w}(t) \geq\right.$ $0)$ or offshore direction $\left(\theta_{w}(t)<0\right)$ are thus modified as follows,

$$
\theta_{w, o n * / o f f *}=\theta_{w, o n / o f f}\left(1 \pm r_{a}\right)
$$

with $r_{a}=\left(T_{a}-T_{d}\right) / T_{d}$ being the acceleration asymmetry $\left(T_{a}\right.$ and $T_{d}$ are the half periods where the acceleration is positive and negative, respectively). The Camenen and Larson model leads to very similar results compared to the Nielsen equation except when $r_{a}>0.7$ where the Nielsen model tends to diverge. Therefore, the acceleration may be assumed to significantly affect the instantaneous friction coefficient and roughness height (and thus the net sediment transport) but not their mean values. The equation proposed in this study (i.e. Eq. 33) should thus be valid independently of the acceleration.

\section{Oscillatory flow data set}

In order to investigate roughness height under plane bed conditions, a wide range of existing data sets were compiled and analyzed. As previously mentioned, a major difficulty in the case of oscillatory motion is to determine the bottom shear stress. Several methods to estimate the total bottom shear stress are presented following a literature review.

\subsection{Methods to estimate bed roughness and total shear stress}

Since at the moment there are no possibility to directly measure the shear stress over a moving bed, several methods are investigated to estimate the bed shear stress. As observed before, these methods lead to the estimation of the equivalent bed shear stress in "clear water" to correctly reproduce the flow over a bed assumed fixed and to compensate for the differences with the real two-phase flow.

\subsubsection{Velocity profile}

The velocity profile in the wave boundary layer can be computed using the turbulent boundary layer momentum equation for unsteady flow. Assuming that the flow inside the boundary layer is essentially horizontal $(w=0)$, the unsteady boundary layer approximation to the Reynolds-averaged horizontal momentum equation with an eddy viscosity closure has the form,

$$
\frac{\partial u}{\partial t}+u \frac{\partial u}{\partial x}=-\frac{1}{\rho} \frac{\partial p}{\partial x}+\frac{\partial}{\partial z}\left(\nu_{T}(z) \frac{\partial u}{\partial z}\right)
$$

where $x$ and $z$ are the horizontal and vertical coordinates, respectively, $u$ is the horizontal velocity, $t$ the time, $p$ the pressure, and $\nu_{T}(z)$ the eddy viscosity. This can be coupled to a flow approximation for the velocity above the boundary layer or freestream velocity $u_{\infty}$ :

$$
\frac{\partial u_{\infty}}{\partial t}=-\frac{1}{\rho} \frac{\partial p}{\partial x}
$$


Neglecting the non-linear convective velocity term $(u \partial u / \partial x \approx 0)$ and recognizing that $\partial u_{\infty} / \partial x=0$, Eqs. 14 and 15 reduce to an equation in terms of velocity difference:

$$
\frac{\partial}{\partial t}\left(u_{\infty}-u\right)=\frac{\partial}{\partial z}\left(\nu_{T}(z) \frac{\partial}{\partial z}\left(u_{\infty}-u\right)\right)
$$

If the wave motion is assumed to be sinusoidal (i.e., $u_{\infty}-u=R e\left(U e^{i \omega t}\right)$ ), the flow velocity within the boundary layer can be expressed by an ordinary differential equation:

$$
\frac{d^{2} U}{d z^{2}}+\frac{d \nu_{T} / d z}{\nu_{T}} \frac{d U}{d z}-\frac{i \omega}{\nu_{T}} U=0
$$

An analytical solution to Eq. 17 (with the boundary conditions $U=u_{\infty}$ at $z=$ $z_{0}=k_{s} / 30$, and $U=0$ for $z \gg \delta_{w}$, where $\delta_{w}$ is the wave boundary layer height) can be obtained close to the bottom for small values of $z_{0} \omega /\left(\kappa u_{*}\right)$ where the logarithmic velocity law can be shown to be valid and the eddy viscosity is a linear function of the vertical position, $v_{T}=\kappa u_{*} z$ (Grant and Madsen, 1986),

$$
\frac{U(z, t)}{U_{w}}=\frac{2}{\pi} \sin \varphi \cos (\omega t+\varphi) \ln \frac{z}{z_{0}}
$$

where $U_{w}$ is the maximum wave orbital velocity and $\varphi$ is the phase lead between free surface and near-bottom wave orbital velocity given by:

$$
\tan \varphi=\frac{\pi / 2}{\ln \frac{\kappa u_{*}}{z_{0} \omega}-1.15}
$$

Thus, it is possible to fit Eq. 18 to an experimental data using $k_{s}$ and $u_{*}$ as they are the only unknowns. Since this method corresponds to the definition of the roughness height introduced for steady currents, it will be subsequently denoted as the "reference method".

\subsubsection{Energy dissipation factor}

Nielsen (1992, pp.146-153) used the experimental data by Carstens et al. (1969) and Lofquist (1986) to estimate the wave energy dissipation factor. In these two data sets are the shear stress time series (Lofquist) and dissipation measurements (Carstens et al.) available for sand beds exposed to oscillatory flows. By assuming that other dissipating mechanisms than friction were negligible in the experiments, the energy dissipation factor $f_{e}$ can be predicted using the Jonsson (1966) relationship,

$$
f_{e}=\frac{D_{E}}{2 /(3 \pi) \rho\left(A_{w} \omega\right)^{3}}=\frac{\overline{\tau_{w}(t) u_{\infty}(t)}}{2 /(3 \pi) \rho\left(A_{w} \omega\right)^{3}}
$$

where $D_{E}$ is the time-averaged rate of energy dissipation due to bed friction, in which $\tau_{w}(t)$ is the instantaneous wave-induced bed shear stress.

Although the two friction-related coefficients $f_{w}$ and $f_{e}$ are different according to their definitions, Nielsen (1992, pp.27-28) showed that the experimental scatter of the measurements of one or the other over natural sand beds is so large that for practical purposes $f_{w}$ and $f_{e}$ can be assumed equal. The roughness height can be calculated inversely using Eq. 10 once $f_{e}$ is determined from experimental data. 


\subsubsection{Momentum equation in the fluid/sediment mixture}

The bed shear stress can also be obtained from the momentum equation for the fluid/sediment mixture. In case of pure oscillatory flow with no superimposed current, the bed shear stress is given by Dick \& Sleath (1991),

$$
\tau_{w}=\int_{z}^{\infty} \frac{\partial}{\partial t}\left(\rho_{m} u-\rho u_{\infty}\right) d z
$$

where $\rho_{m}$ is the density of the fluid/sediment mixture,

$$
\rho_{m}=(1-C) \rho+C \rho_{s}
$$

in which $C$ is the volumetric sediment concentration.

However, prediction of bottom shear stress using the above relation requires additional assumptions on the concentration $C$, which varies in the moving layer from 0.1 to 0.6 (Wijetunge \& Sleath, 1998). Another difficulty is to define the height where the bed shear stress $\tau_{w}$ is calculated. Dick \& Sleath (1991) proposed to use the initial bed level. It seems that the still bed level during grain motion is more appropriate but it is not easy to define (where the maximum concentration is reached). The roughness height is calculated as in section 3.1.2 where $f_{w}$ is deduced from the definition of the shear stress (cf. Eq. 9).

This method differs from the others as it is supposed to give the "real" bed shear stress under the sheet flow layer and not the "equivalent" bed shear stress.

\subsubsection{Sheet flow layer thickness}

In a series of experimental studies with steady flow, Wilson \& Pugh (1989) and Pugh \& Wilson (1999) showed that the roughness height is proportional to the thickness of the moving layer $\delta_{s}$ (defined as the difference between the top of the moving bed level and the still bed level) with a factor 0.5. Wilson (1989) made an analysis of the sheetflow friction during oscillatory motion and proposed a similar relationship, which may be written,

$$
k_{s}=\alpha_{s} \delta_{s}=\alpha_{\theta} d_{50} \theta
$$

where $\alpha_{s}=0.5$ and $\alpha_{\theta}=5$ were suggested by Wilson (1989).

Based on experimental evidence, Asano (1992) suggested that the erosion depth $\delta_{b}$ (defined as the difference between the initial bed level and the still bed level after sheet flow started) is governed by the dynamic Coulomb criterion, which states that a shear stress and its normal stress are proportional. The normal stress at the bottom consists of static pressure of the particle lattice, dispersive pressure due to particle collisions, and pore-fluid turbulence stress. Applying this criterion at the boundary between the mobile and immobile layers yields the following relationship (the bed shear stress is defined at the still bed level contrary to Dick \& Sleath),

$$
\tau_{w,-\delta_{b}}=\int_{-\delta_{b}}^{0} \rho g(s-1) C \tan \phi_{r} d z
$$


where $\phi_{r}$ is the critical dynamic angle of internal friction. Assuming that $C$ and $\phi_{r}$ are constant over the layer, the erosion depth can be related to the Shields parameter $\theta$ :

$$
\frac{\delta_{b}}{d_{50}}=\frac{\theta}{\bar{C} \tan \phi_{r}}
$$

Approximate estimates of $\bar{C}$ and $\phi_{r}, \bar{C} \approx 0.4$ and $\phi_{r}=30^{\circ}$ in Eq. 25, yields:

$$
\frac{\delta_{b}}{d_{50}}=5 \theta
$$

Since $\delta_{b}<\delta_{s}$, and as Wilson (1989) deduced $\alpha_{s}$ from $\alpha_{\theta}$, this means that the coefficient $\alpha_{s}>1$, which yields a value that is at least twice as large as the one proposed by Wilson (1989). It should be noted that, depending on the way the sheet flow layer is estimated (visual observations, concentration profile including the "tail", or linearly extrapolated to zero), strong differences may be observed. Indeed, Sumer et al. (1996) estimated the thickness of the sheet-flow layer from visual observations and from the concentration profiles. Using the second method, values of $\delta_{s}$ were twice as large as values obtained using the first one. The value $\alpha_{s}=1$ is used for this study.

\subsubsection{Bed-load sediment transport}

Another method to estimate the roughness height is proposed here. If the net sediment transport rate is known (over a half-cycle or a full cycle) and assuming a quasi-steady behavior for the sediment transport (no phase lag between the fluid velocity and the sediment concentration), the effective Shields parameter can be derived employing a sediment transport formula that describes the relationship between the Shields parameter and the sediment transport rate over flat beds. It should be noted that this method to estimate the roughness height would be biased if strong wave acceleration or boundary layer streaming is present. These effects may indeed influence the roughness height (Nielsen, 2002, Myrhaug and Holmedal, 2005). Nielsen (1992) proposed to use the Meyer-Peter \& Müller formula (1948), but in the present study, the Soulsby (1997) formula was preferred since it was based on the quasi-steady integration of the Nielsen formula over a half wave cycle ( $c f$. Camenen and Larson, 2005),

$$
q_{s, 1 / 2}=a_{w} \sqrt{g(s-1) d_{50}^{3}}\left(\bar{\theta}-\theta_{c r}\right)^{3 / 2}
$$

where $a_{w}=5.1, \bar{\theta}$ is the mean value over a wave half-period of the instantaneous Shields parameter $(\bar{\theta}=0.5 \theta$ for sinusoidal waves $)$, and $\theta_{c r}$ is the critical Shields parameter for incipient movement of the sediment. Even tough both the Meyer-Peter \& Müller and Soulsby formulas originally included the grain roughness only, Camenen \& Larson (2005) showed that these formulas performed well for sheet flow transport in steady flows using the total or equivalent bed shear stress. Once the Shields parameter has been determined from the sediment transport data, the friction factor and the roughness height can easily be estimated using Eq. 10.

For the full cycle data (asymmetric waves), the net measured sediment transport is obtained from $q_{s, \text { net }}=q_{s, 1 / 2, \text { crest }}-q_{s, 1 / 2, \text { trough }}$, where $q_{s, 1 / 2, \text { crest }}$ and $q_{s, 1 / 2, \text { trough }}$ are 
calculated from Eq. 27 using $\overline{\theta_{1 / 2, \text { crest }}}$ and $\overline{\theta_{1 / 2, \text { trough }}}$, respectively. The time-averaged Shields parameters are based on the assumption that the friction factor is constant over the wave period (discussed in Camenen \& Larson, 2005). Thus, the parameter values are only functions of the velocity time series. Assuming a wave velocity profile following Stokes 2 nd-order wave theory (i.e. $u_{w}(t)=U_{w}\left[\cos \omega t+r_{w} \cos 2 \omega t\right]$, where $r_{w}$ is the wave asymmetry and $\left.\omega=2 \pi / T_{w}\right)$ with a half-period equal to $T_{w} / 2$ for both crest and trough, the following relationship is obtained (see appendix in Camenen \& Larson, 2007b):

$$
\frac{\overline{\theta_{1 / 2, \text { crest }}}}{1+\frac{13}{3 \pi} r_{w}+r_{w}^{2}} \approx \frac{\overline{\theta_{1 / 2, \text { trough }}}}{1-\frac{13}{3 \pi} r_{w}+r_{w}^{2}} \approx \bar{\theta}
$$

After simple algebraic manipulations, $q_{s, n e t}$, to the first order of $\theta_{c r} / \bar{\theta}$ and $r_{w}$, is approximated by:

$$
q_{s, n e t} \approx \frac{13}{\pi} r_{w} a_{w} \sqrt{g(s-1) d_{50}^{3}} \bar{\theta}^{3 / 2}
$$

Eq. 29 is valid only if the bed shear stress largely exceeds its critical value for the inception of transport and $r_{w} \ll 1$.

\subsection{Data sets}

Table 2 summarizes the compiled data sets, where the type of flow motion (experimental set-up), the methods used to estimate the roughness, the number of data points, the sediment properties (material used, density, median grain size) as well as the range of values for the main hydrodynamic parameters (wave orbital velocity and period, skin Shields parameter) are listed.

It can be observed that most of the data are from Oscillating Water Tunnels (OWT). This kind of experiment has one advantage for this study: large orbital velocities and Shields parameters can be reached (sheet flow regime). Previously, experimental studies were often carried out using an Oscillating Tray (OT; oscillating bed in a tank of still water, cf. Sleath, 1978). More recently, some experiments by Dohmen-Janssen \& Hanes (2002) were carried out in a Large Wave Flume (LWF). Also, light material was often used for experiments on sheet flow regime and velocity profiles, whereas sand was generally used for experiments on sediment transport.

All data where ripples were observed were discarded. For many cases where the Shields parameter is relatively low, ripples are expected to occur. However, for all the case used in this study, the ripples did not have time to develop (half cycle experiments). In case of the data set by Watanabe \& Asano (1990), the observed plane bed may be because the measurements were carried out before the ripples develop.

In Eq. 27, it is assumed that the contribution from suspended load amounts to only a small (i.e., negligible) fraction of the total load. Based on experiments, DohmenJanssen (1999) estimated that suspended load typically consists of approximatively 20 $\%$ of the total load for high-stress data in OWT experiments, which is in agreement with this assumption. It should also be noted that for the method using the bed load transport formula over a full cycle, phase lag effects can occur and influence the result. The Dohmen-Janssen (1999) criterion has been used in order to eliminate the data for 


\begin{tabular}{|c|c|c|c|c|c|c|c|c|c|}
\hline Author(s) & Facility & Exp. measurements for $k_{s}$ & Nbr. & Mat. & $s$ & $\boldsymbol{d}_{50}(\mathrm{~mm})$ & $\boldsymbol{U}_{\boldsymbol{w}}(\mathrm{m} / \mathrm{s})$ & $\boldsymbol{T}_{\boldsymbol{w}}(\mathrm{s})$ & $\boldsymbol{u}_{*}(\mathrm{~m} / \mathrm{s})$ \\
\hline Sleath, 1978 & OT & $q_{s}($ half cycle) & 22 & sand & 2.66 & $1.9,4.2$ & $0.2-0.7$ & $0.5-2.7$ & - \\
\hline & & & 12 & nylon & 1.14 & 3.0 & $0.07-0.17$ & $1.3-8.9$ & - \\
\hline Horikawa et al., 1982 & OWT & $q_{s}$ (half cycle) & 6 & sand & 2.66 & 0.2 & $0.7-1.3$ & $3.6-6.0$ & - \\
\hline Sawamoto \& Yamashita, & OWT & sheet flow layer & 14 & sand & 2.65 & $0.7,1.8$ & $0.7-1.3$ & 3.8 & - \\
\hline 1986 & & $q_{s}($ half cycle) & 7 & PVC & 1.58 & 1.5 & $0.4-1.3$ & 3.8 & - \\
\hline Sleath, 1987 & OWT & momentum equation & 14 & sand & 2.65 & $0.2-30$ & $0.05-0.7$ & $4.5-4.6$ & $0.02-0.10$ \\
\hline Ahilan \& Sleath, 1987 & OWT & $q_{s}($ half cycle) & 5 & nylon & 1.137 & 4.0 & $0.3-1.5$ & $3.6-3.7$ & - \\
\hline & & & 4 & $\mathrm{PVC}$ & 1.44 & 4.3 & $1.1-1.2$ & $4.7-4.9$ & - \\
\hline Watanabe \& Isobe, 1990 & OWT & $q_{s}($ full cycle $)$ & 11 & sand & 2.65 & $0.2,0.9$ & $0.27-0.43$ & 3,6 & - \\
\hline King, 1991 & OWT & $q_{s}$ (half cycle) & 178 & sand & 2.65 & $0.1-1.1$ & $0.3-1.2$ & $2-12$ & - \\
\hline Dick \& Sleath, 1991 & OWT & momentum equation, & 17 & acrylic & 1.141 & 0.7 & $0.3-0.9$ & $2.5-4.5$ & $0.04-0.12$ \\
\hline & & velocity profile, sheet flow layer & 8 & nylon & 1.137 & 4.0 & $0.3-0.8$ & $2.5-4.6$ & $0.06-0.16$ \\
\hline $\begin{array}{lcc}\text { Nielsen, } 1992 \text { (data } & \text { from } \\
\text { Carstens et al, 1969) } & \end{array}$ & flume & energy dissipation & 16 & sand & 2.65 & $0.19-0.3$ & - & - & - \\
\hline Dibajnia \& Watanabe, 1992 & OWT & $q_{s}($ full cycle $)$ & 25 & sand & 2.65 & 0.2 & $0.6-1.0$ & $1-4$ & - \\
\hline Ribberink \& Chen, 1993 & OWT & $q_{s}($ full cycle $)$ & 4 & sand & 2.65 & 0.13 & $0.6-1.2$ & 6.5 & - \\
\hline Ribberink \& Al Salem, 1994 & OWT & $q_{s}$ (full cycle) & 10 & sand & 2.65 & 0.2 & $0.7-1.3$ & $5-12$ & - \\
\hline Asano, 1995 & OWT & sheet flow layer, $q_{s}$ (half cycle) & 15 & plastic & 1.24 & 4.17 & $0.5-1.0$ & $4.3-5.6$ & - \\
\hline & & & 5 & plastic & 1.317 & 3.01 & $0.8-1.0$ & $4.3-5.3$ & - \\
\hline Li \& Sawamoto, 1995 & OWT & sheet flow layer & 15 & glass & 2.45 & 1.0 & $1.4-1.9$ & $2.3-3.1$ & - \\
\hline & & & 12 & sand & 2.65 & 1.35 & $1.9-2.4$ & $2.4-3.4$ & - \\
\hline & & & 11 & plastic & 1.50 & 5.0 & $0.5-0.8$ & $4.0-5.3$ & - \\
\hline Zala Flores \& Sleath, 1998 & OWT & sheet flow layer & 9 & sand & 2.65 & 0.41 & $2.0-2.2$ & $5.6-7.1$ & - \\
\hline & & & 12 & PVC & 1.44 & 4.3 & $0.4-0.8$ & $2.5-3.1$ & - \\
\hline & & & 6 & acrylic & 1.141 & 0.7 & $0.3-0.5$ & $2.5-2.6$ & - \\
\hline Wijetunge \& Sleath, 1999 & OWT & $\begin{array}{l}\text { momentum equation, energy } \\
\text { dissipation, sheet flow layer }\end{array}$ & 26 & nylon & 1.137 & 4.0 & $0.6-0.9$ & $3.4-4.4$ & $0.05-0.10$ \\
\hline Dohmen-Janssen et al, 2001 & OWT & velocity profile, sheet flow layer & 19 & sand & 2.65 & $0.13-0.32$ & $0.5-1.5$ & 7.2 & $0.3-3.0$ \\
\hline Dohmen-Janssen \& Hanes, 2002 & LWF & sheet flow layer, $q_{s}$ (full cycle) & 14 & sand & 2.65 & 0.24 & $0.6-1.5$ & $6.5,9.1$ & $1.0-2.6$ \\
\hline Ahmed \& Sato, 2003 & OWT & sheet flow layer, $q_{s}$ (full cycle) & 12 & sand & 2.65 & $0.21-0.74$ & $0.97-1.54$ & 3.0 & - \\
\hline O'Donoghue \& Wright, 2004 & OWT & sheet flow layer, $q_{s}$ (full cycle) & 22 & sand & 2.65 & $0.15-0.51$ & $1.1,1.3$ & $5.0,7.5$ & - \\
\hline
\end{tabular}


which significant phase lag occurs, where a steady equation (Eq. 27) for the bed load is not valid,

$$
p_{p l}=\frac{\delta_{s} \omega}{W_{s}}>0.5
$$

where $p_{p l}$ is a phase-lag parameter and $W_{s}$ is the sediment fall speed.

\subsection{Validation of analysis methods}

As mentioned above, the "velocity profile" method may be considered as the "reference method". Thus, using data sets where the "velocity profile" method and other method can be employed, it is possible to make comparisons for validation of the methods.

\subsubsection{Momentum equation in the fluid/sediment mixture}

Dick \& Sleath (1991) estimated the bed shear stress using both "velocity profile" and "momentum equation" methods. A comparison between the two methods (see Fig. (1a) produced very good agreement after the shear stress estimated from the "momentum equation" method was multiplied by 2 . The underestimation due to the choice of initial bed level for calculating the bed shear stress or the influence of sand concentration on the flow only included in the "momentum equation" method may explain this systematic difference.

\subsubsection{Energy dissipation}

For the "energy dissipation factor" method proposed by Nielsen (1992), no other measurements were found to validate this method. Wijetunge \& Sleath (1998) measured both friction and energy dissipation coefficients at the levels $z=0$ and $z=-\delta_{b}$. The friction coefficient was estimated from the momentum equation in the fluid/sediment mixture. It appears that $f_{e}$ and $f_{w}$ are somehow related; but the assumption $f_{e} \approx f_{w}$ is not validated.

\subsubsection{Sheet flow layer thickness}

Several authors found a relationship between the erosion depth $\delta_{b}$ and the Shields parameter based on theoretical or experimental investigations (see Asano's relationship, Eqs. 25] and 26),

$$
\delta_{b}=\alpha_{b} \theta^{\beta_{b}} d_{50}
$$

with $\left(\alpha_{b}, \beta_{b}\right)=(3,3 / 4)$ following Sawamoto \& Yamashita $(1986),\left(\alpha_{b}, \beta_{b}\right)=(8.5,1)$ following Asano (1992), and $\left(\alpha_{b}, \beta_{b}\right)=(3,1)$ following Zala-Flores \& Sleath (1998). Dohmen-Janssen (1999) proposed different values depending on the grain size, i.e., $\left(\alpha_{b}, \beta_{b}\right)=(7.8,1)$, if $d_{50}<0.2 \mathrm{~mm}$, and $\left(\alpha_{b}, \beta_{b}\right)=(3.5,1)$, if $d_{50} \geq 0.2 \mathrm{~mm}$. However, most of these authors computed the Shields parameter using the skin friction.

Fig. 2a depicts $\delta_{b} / d_{50}$ versus the total Shields parameter, where the roughness height is estimated as $k_{s}=\delta_{b}$. Although the uncertainties remain quite large, most of the data points are found to be surrounded by the equations proposed by Asano 
(a)
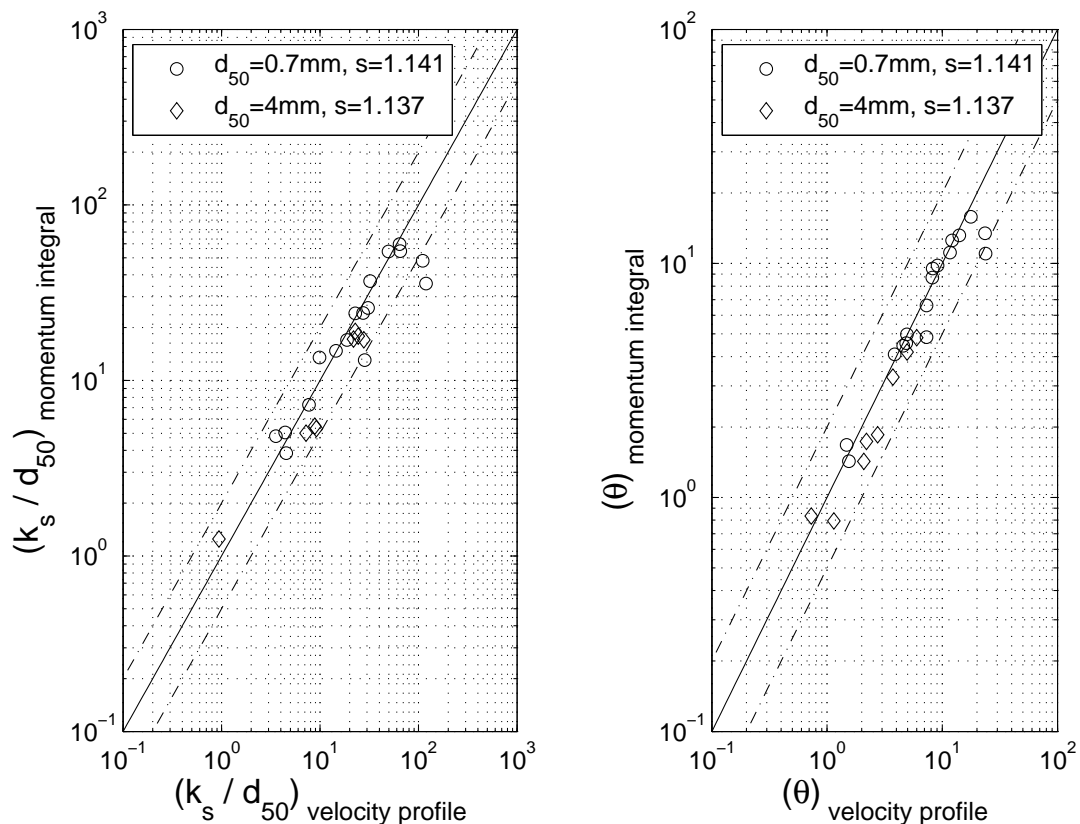

(b)
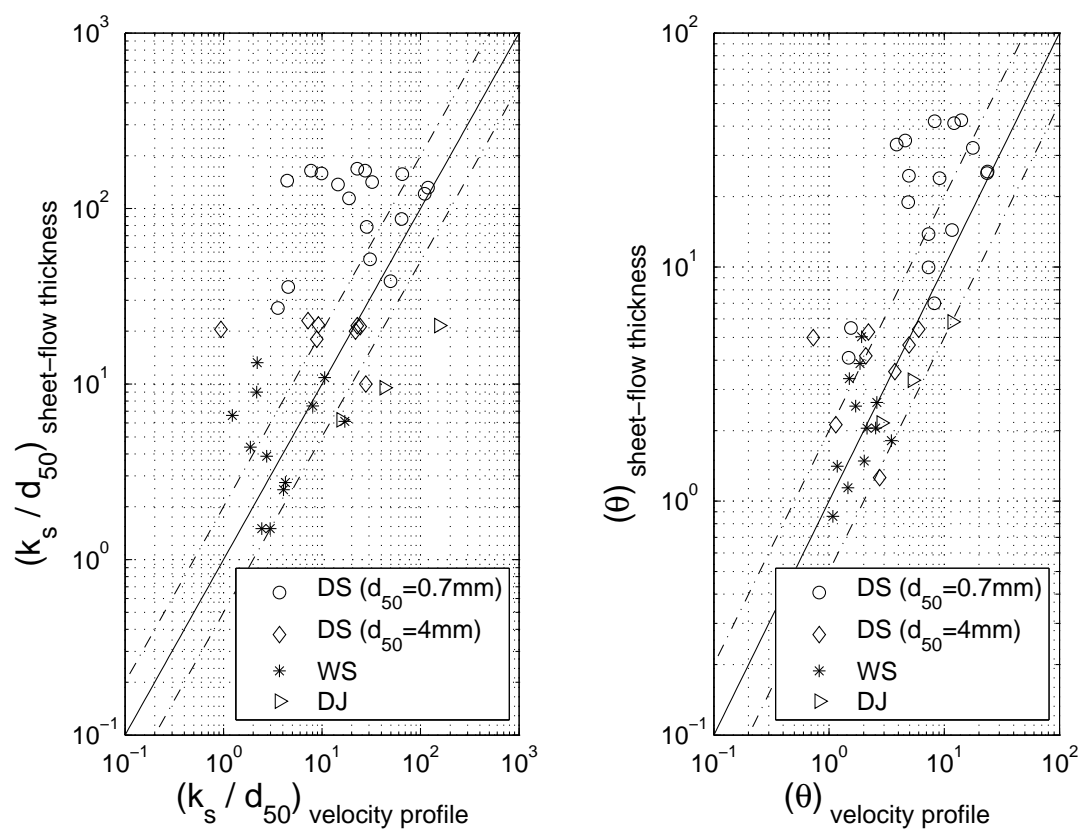

Figure 1: Validation of the "momentum equation" method (a) and "sheet flow thickness" method (b) against the "velocity profile" method (solid line corresponds to a perfect agreement, dashed lines to an agreement within a factor 2; data from Dick \& Sleath, 1991 in (a); DS: Dick \& Sleath, 1991, WS: Wijetunde \& Sleath, 1998, DJ: Dohmen-Jansen et al., 2001 in (b)). 
and Zala Flores \& Sleath (The Asano equation tends to overestimate the results as he used the skin Shields parameter to fit it, which leads to a horizontal shift). As observed by O'Donoghue \& Wright (2004), the correlation between the erosion depth and the Shields parameter seems to occur after a critical value for the Shields parameter corresponding to the inception of sheet flow $\left(\theta_{c r, s f} \approx 0.8\right)$. Using this methodology, it seems that the erosion depth (and the sheet-flow layer thickness) is proportional to the Shields parameter to the power $\beta_{b}$, with $0.75 \leq \beta_{b} \leq 1$, except for the Wijetunge \& Sleath data set where $\beta_{b}=1.5$. This means that the previous hypothesis $\left(k_{s}=\delta_{b}\right)$ is reasonable.

(a)

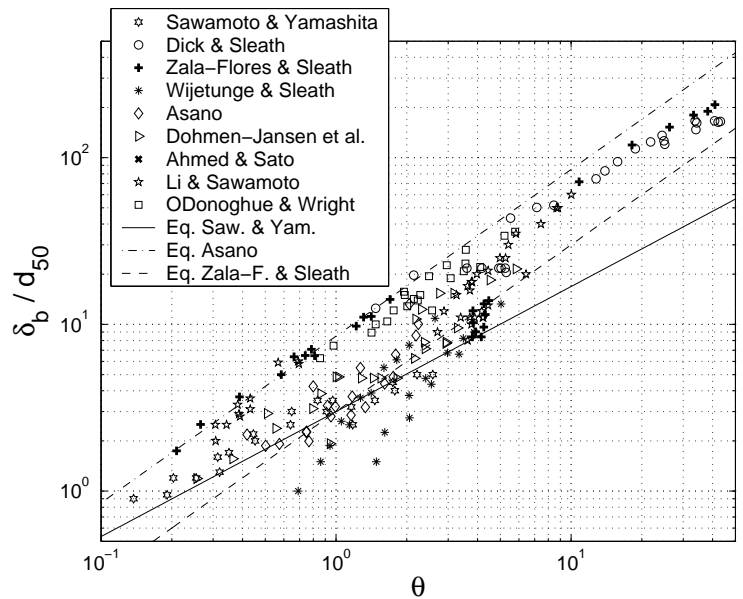

(b)

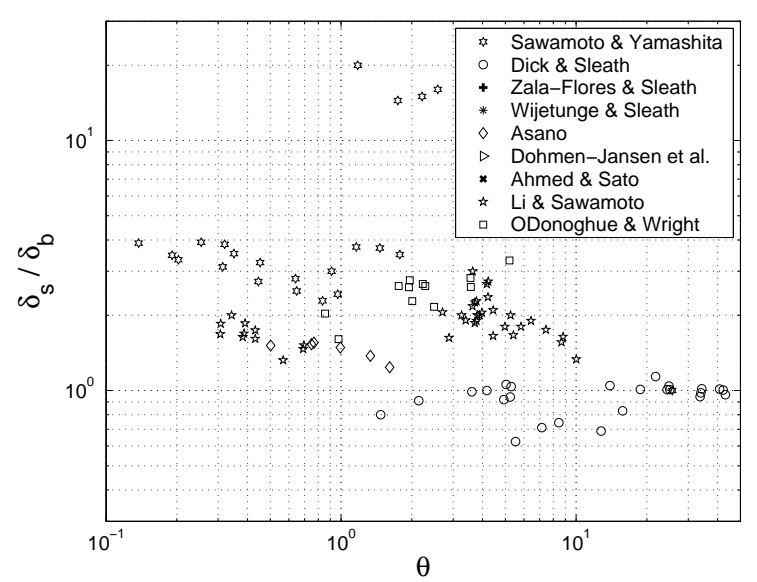

Figure 2: (a) Erosion thickness $\delta_{b}$ and (b) the ratio $\delta_{s} / \delta_{b}$ versus the total Shields parameter calculated using the relationship $k_{s}=\delta_{b}$.

In Fig. 2b is $\delta_{s} / \delta_{b}$ plotted versus the total Shields parameter where the roughness is estimated as $k_{s}=\delta_{s}$. It can be observed that the sheet flow layer thickness tends to be equal to the erosion thickness when the Shields parameter reaches a critical value varying from 1 to 10. The four points (from Sawamoto \& Yamashita data set) where the $\delta_{s} / \delta_{b}$-value is large correspond to cases where suspension occurred, which markedly affected the results. The data from Dick \& Sleath, where $\delta_{s}<\delta_{b}$, can also be explained since the sand may have been arranged loosely before the experiment and packing occurred when the sheet flow regime appeared. For lower shear stress, a maximum value is reached of $\delta_{s} / \delta_{b}=3-4$. It may correspond to an intermediate regime at the beginning of the sheet flow regime, where instability effects on the movement of each particle are larger (vertical movement not negligible), and where the bed level slightly rises. Assuming suspended sediment is negligible, by conservation of sediment, the relation $\delta_{s} / \delta_{b}=C_{\max } / \bar{C}$ is obtained. Assuming $\bar{C}=0.4$ and $C_{\max }=0.6, \delta_{s} / \delta_{b}=1.5$ would be expected. Based on this assumption and Fig 2 , the sheet flow layer seems to be loose $(\bar{C} \approx 0.1-0.2)$ for relatively low shear stress and is getting very dense $\left(\bar{C} \approx C_{\max }\right)$ for large shear stress.

As a first approximation, it may be assumed that $k_{s}=\delta_{s}$. It may be noted that Sumer et al. (1996) observed a similar relationship as Eq. 31 for steady flow with 
$\left(\alpha_{b}, \beta_{b}\right)=(5,1)$. For the same data set, the equation proposed by Wilson (1966) that $k_{s}=5 \theta d_{50}$, shows good agreement. This means $k_{s} \approx \delta_{s}$

Dick \& Sleath (1991), Wijetunge \& Sleath (1998) and Dohmen-Janssen et al. (2001) estimate the bed shear stress using the "velocity profile" method and measured the sheet flow layer thickness (or erosion depth). A comparison between the results obtained employing the two methods (see Fig. 1b) presents a larger discrepancy than for the "momentum equation" method. An overestimation of the results is often observed mainly for the data from Dick \& Sleath. However, this could be explained similarly as for Fig. 2 2 ; the Dick \& Sleath data set corresponds to the highest values of $\delta_{b} / d_{50}$ observed. It should be remembered that some discrepancy may result from the way the sheet flow layer thickness is estimated.

\subsubsection{Bed-load sediment transport}

The validation of the "bed load transport" method is not as easy as for the previous methods since no data set was found where both sediment transport under waves only and the velocity profiles were measured. Nnadi \& Wilson (1992) performed experiments for steady currents in pressurized closed conduits where the roughness height $k_{s}$ could be computed using both the classical Nikuradse equation (assuming a logarithmic velocity profile) and employing measured bed load transport rate. The Meyer-Peter \& Müller formula was utilized to estimate the roughness height from these bed-load data . As observed by Bayram et al. (2003, see Fig. 1), these two different methods are highly correlated, especially for the experimental data with sand. However, the "bed-load transport" method seemed to yield results that depend on the sediment density. Through this validation, it is however believed that the two methods used here to estimate $k_{s}$ under oscillatory flow are compatible.

Finally, the data sets from Sawamoto \& Yamashita (1986), Asano (1995), DohmenJanssen \& Hanes (2002), Ahmed \& Sato (2003), and O'Donoghue \& Wright (2004) present measurements of both the sheet-flow layer thickness and the net sediment transport. Assuming that the "sheet-flow layer" method gives accurate results with $\delta_{s}=k_{s}$, it is possible to validate the "bed-load transport" method. Unfortunately, for the data sets of Ahmed \& Sato and O'Donoghue \& Wright, since strong phase-lag effects occurred, only a limited portion of the data could be used since the Soulsby formula (1997, cf. Eq. 27) for the estimation of the bed load was not valid anymore. The selection of the data points was made using the relationship by Dohmen-Janssen (1999) that yields $2 \pi \delta_{s} /\left(W_{s} T_{w}\right)>0.35$ (limit above which quasi-steady models are not valid).

Fig. 3 illustrates variations of $k_{s}$ and $\theta$ using both "bed-load transport" and "sheetflow layer thickness" methods. Dohmen-Janssen \& Hanes (2002) showed that the thickness of the sheet-flow layer varies with time and measured $\delta_{s}$ over a wave period. The $\delta_{s}$-values observed at the crest and at the trough of the waves were plotted. The induced Shields parameters correspond to the maximum value at the crest and at the trough, defined as follows,

$$
\theta_{\text {crest } / \text { trough }}=\frac{1 / 2 f_{w, \text { crest } / \text { trough }} u_{w, \text { crest } / \text { trough }}{ }^{2}}{(s-1) g d_{50}}
$$


where $f_{w, \text { crest }}$ and $f_{w, \text { trough }}$ are the friction coefficients calculated using Eq. 10 with $k_{s}=\delta_{s, \text { crest }}$ and $k_{s}=\delta_{s, \text { trough }}$ respectively. The results observed in Fig. 3 show fairly good agreement between the two methods, though with marked dispersion. However, for the Sawamoto \& Yamashita data set, it seems that a lower value on $\alpha_{b}$ would imply better results. This can easily be explained as $\delta_{s} / \delta_{b} \approx 3$ for most of the cases in this data set (see Fig. 2b). Moreover, the large underestimation observed for the remaining Ahmed \& Sato and O'Donoghue \& Wright data may be caused by the phase-lag effects occurring in these data. Indeed, the criterion proposed by Dohmen-Jansen ( $c f$. Eq. [30) is nearly fulfilled $\left(0.3<p_{p l}<0.5\right)$ for most of these cases.
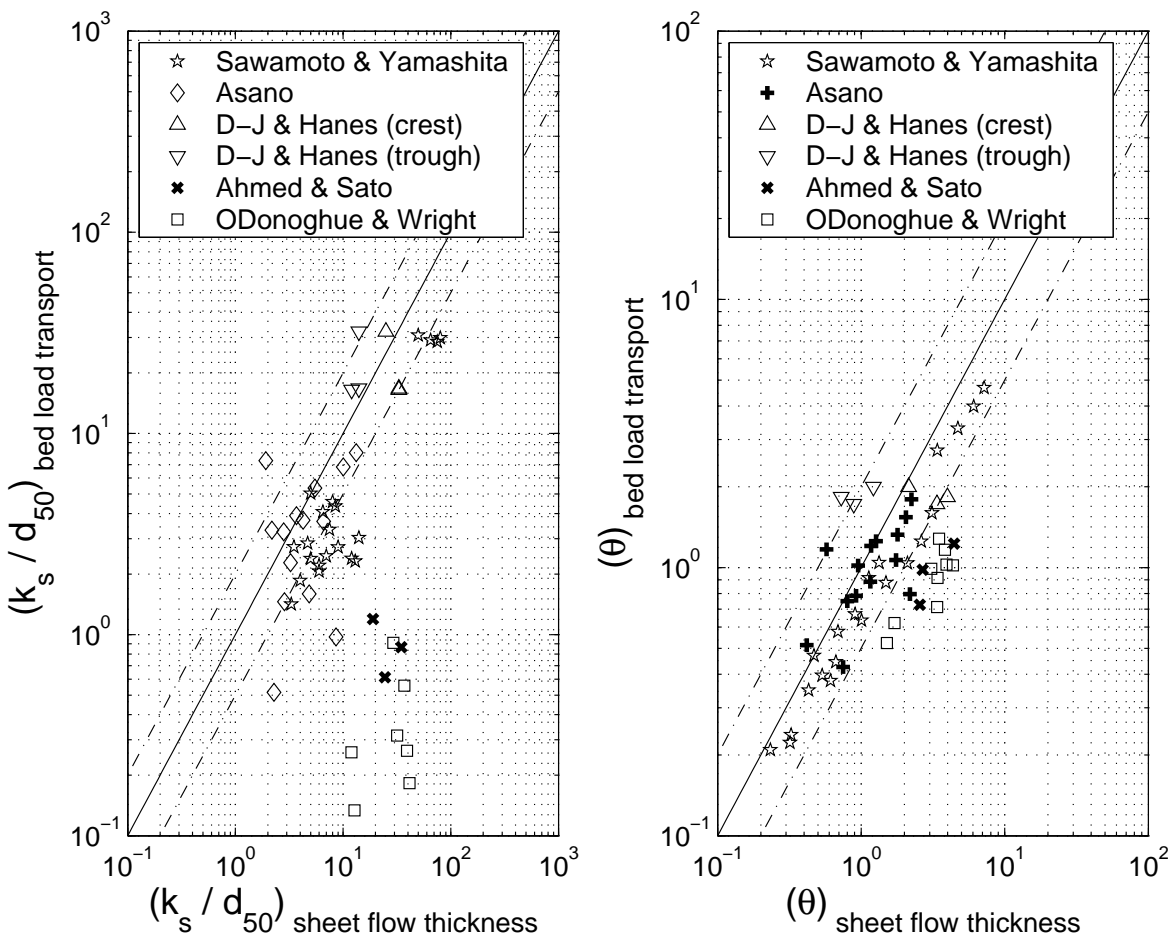

Figure 3: Validation of the "bed-load transport" method against the "sheet flow thickness" method (solid line corresponds to a perfect agreement, dashed lines to an agreement within a factor 2).

\section{Roughness height for plane bed under oscillatory flow}

\subsection{Comparison between existing roughness height relation- ships and data}

In order to make the results clearer and to understand the limits of each method used, the data have been plotted in three separate figures depending on the method 
employed. In Fig. 化 are the results from the "velocity profile", "momentum equation" and "energy dissipation" methods plotted; in Fig. 4b from the "boundary layer" method; and in Fig. 45 from the "bed-load transport" method. The three figures present the effective roughness ratio versus the total Shields parameter based on the "measured" $k_{s}$. Also, the semi-empirical relationships from the literature to predict roughness height are shown in all the graphs. The Grant \& Madsen equation (1982) could not be plotted on the same graph, since it depends on the skin Shields parameter.

In Fig. 4a, it is clear that the data points and the fitted curve from the "energy dissipation method" proposed by Nielsen (1992, pp.152-155) show a totally different behavior than the other data sets and formulas. However, the larger roughness heights obtained by Nielsen might be explained by the fact that the plane regime was unstable (the measurements were taken before ripples had time to form). As shown in Sec. 3.1.2, the assumption $f_{e} \approx f_{w}$ seems not to be satisfactory (at least for this case). These data points will thus be rejected in the following study.

The equation proposed Xu \& Wright (1993) tends to overestimate the roughness height for most of the cases. The Wilson (1989) and Ribberink (1998) formulas yield much more accurate results. The slope $\beta$ (see Eq. 1) observed from the data points appears to be higher than 1 ( $\beta \approx 1.5$ using a least-square fit). Furthermore, the data from Sleath (1987) confirm that a minimum value of $k_{s} / d_{50}$ exists when the Shields parameter is lower than 1 (no sheet flow), corresponding to a fixed bed. However, the classical value observed by Kamphuis (1974) and Yalin (1977), and confirmed by Camenen et al. (2006), i.e., $k_{s} / d_{50}=2$, overestimates the results for this data set.

The roughness heights obtained using the "sheet-flow layer" method (see Fig. 4b) display a slightly different behavior. Indeed, the observed slope is $\beta \approx 1$, but this could easily be explained by the basic assumption of this method, i.e., $k_{s} \propto \delta_{s}$ (Eq. 23), since $\delta_{s}\left(\right.$ or $\delta_{b}$ ) is proportional to the Shields parameter to the power 1 ( $c f$. Eqs 25 and 31 and Fig. 21). It should also be noted that the data from Dohmen-Janssen \& Hanes (2002) obtained in a large wave flume show larger roughness height values for a fixed Shields parameter compared to the data from OWT. However, Dohmen-Janssen \& Hanes showed that the experimental set-up does not really influence the thickness of the sheet flow layer. The main difference appeared to be the way to estimate the sheet-flow layer thickness: they calculated it from the sediment concentration profiles, while previous authors used visual estimations. Moreover, Ahmed \& Sato (2003) used a PIV system to predict the sheet-flow layer thickness that apparently also displayed larger observed values on the sheet-flow layer thickness for a fixed Shields parameter.

Finally, the results obtained through the "bed-load transport" method (see Fig. 4k) tend to confirm those from "velocity profile" and "momentum equation" methods: the slope $\beta$ determined by least-square fitting toward the data points appears to be higher that $1(\beta \approx 1.5)$. Also, the observed roughness heights are generally larger than for the previous methods when $\theta>1$. When $\theta<1$, the obtained results are very scattered with $k_{s} / d_{50}$ varying from 0.1 to 10 . For some data from Watanabe \& Isobe, the Shields parameter being very close to its critical value, the results obtained using Eq. 29 may be also distorted (underestimated). However, Camenen et al. (2006) observed a similar dispersion for the estimation of the roughness height under steady currents and for relatively low shear stress. 

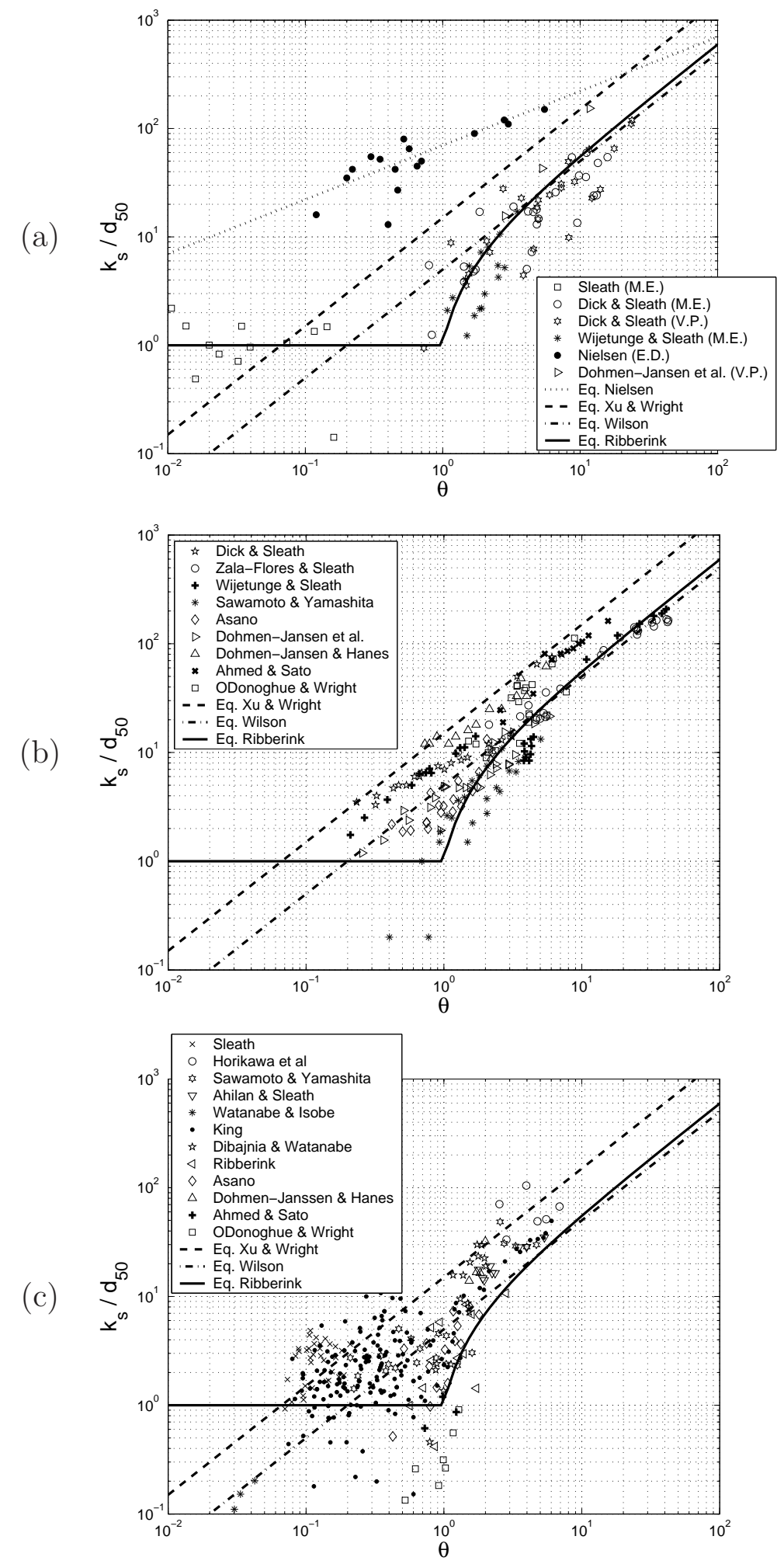

Figure 4: Effective roughness ratio versus total Shields parameter, together with semiempirical predictive relationships, including data obtained using (a) the "velocity profile" (V.P.), "momentum equation" (M.E.) and "energy dissipation" (E.D.) methods; (b) the "sheet flow layer" method; and (c) the "bed-load transport" method. 


\subsection{A new relationship}

\subsubsection{Analogy to steady current}

Based on a study on the vertical velocity profile above a sheet-flow layer, Wilson (1989) observed an analogy between steady and oscillatory sheet flow: "Mobile beds at high shear stress are neither smooth boundaries nor rough ones, but obey their own frictional law, analogous to the other cases but with length scale proportional to the sheet-flow thickness $\delta_{s}$. It follows that sheet-flow behavior can be made formally equivalent to the rough-boundary case by setting the equivalent Nikuradse sand-grain roughness $k_{s}$ equal to a multiple of $\delta_{s}$ " for both steady and oscillatory flows. Ribberink (1998) followed this idea and suggested that a constant representative value for $k_{s}$ may be used during the wave cycle. He proposed a similar formula for steady and oscillatory flows (apart from the grain-related or skin roughness that he assumed different for a steady flow, $k_{s}=3 d_{90}$, and for an oscillatory flow, $k_{s}=d_{50}$ ), that is function of the Shields parameter and the sediment grain size. Zala Flores \& Sleath (1998) also observed that the flow may be considered as quasi-steady for the sheet-flow regime at relatively low shear stresses as pressure gradient and inertia forces are negligible. They found that the sheet-flow thickness may thus be proportional to the Shields parameter times the medium grain size. When the instantaneous shear stress reaches its maximum, if there is no phase-lag between the flow and the shear stress, the acceleration is zero and the shear stress should act similarly to a steady flow. This means that the effective roughness ratio may be a function of the maximum wave-induced Shields parameter in the same way as for a steady current.

Thus, following the results from Camenen et al. (2006), it is hypothesized that the relationship could be written $k_{s} / d_{50} \propto \theta^{1.7}$ as soon as the Shields parameter reaches a critical value. The value $\beta=1.7$ is quite close to the slope observed for the data in the graphs of Fig. 4. A new equation for the roughness height for plane bed under oscillatory flow is proposed,

$$
\frac{k_{s}}{d_{50}}=a+b\left(\frac{\theta}{\theta_{c r, u r}}\right)^{1.7}
$$

where $a$ and $b$ are coefficients $((a, b)=(0.6,2.4)$ for steady flows, $c f$. Camenen et $a l ., 2006)$ and $\theta_{c r, u r}$ corresponds to the limit between the lower-regime and the upperregime. The upper-regime may be defined as the regime where $k_{s}$ is no more a function of the grain size only. On the other hand, the lower-regime may be define as the regime $k_{s}$ is only a function of the grain size (skin friction). If $\theta<\theta_{c r, u r}, k_{s}<3 d_{50}$, which corresponds approximately to the skin friction.

In Fig. 5 (where all the data were used apart from the "energy dissipation" method since it was not validated against any other method and the results are quite different from the other methods), the effective roughness ratio is plotted versus the total Shields parameter with the different sediment densities used for the experiments emphasised. It may be noted that the differences observed in section 4.1 may not only be due to the different methods used to compute the roughness height but also due to the different kind of sediments used in the various experiments. Indeed, it appears that in all the experiments where the "velocity profile" method was applied, the sediment density 
was particularly low. This may imply that the effective roughness ratio is not only a function of the Shields parameter but also a function of the sand characteristics (such as the sediment density) or the flow characteristics.

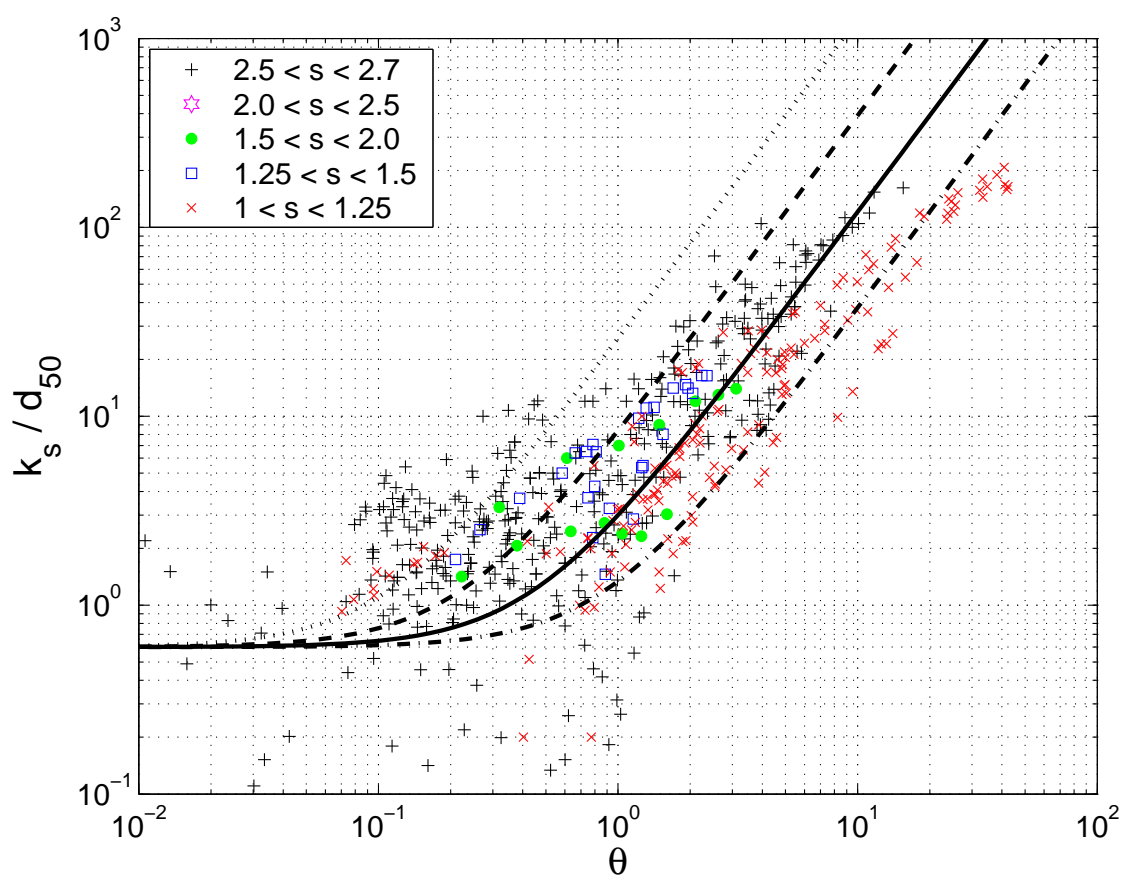

Figure 5: The effective roughness ratio versus the total Shields parameter (using all data apart from the "energy dissipation" method) including the influence of sediment density (the dotted, dashed, solid, and dashed-dotted lines correspond to Eq. 33 with $a=0.6$ and $b=2.4$, and $\theta_{c r, u r}=0.25,0.5,1.0$ and 2.0, respectively).

\subsubsection{Critical Shields parameter for the upper regime}

The main objective of the present study is to develop a new predictive formula for the roughness height that can perform satisfactory under a wide range of conditions. A sensitivity analysis was made to estimate the influence of the main parameters, which are the median grain size $d_{50}$, the settling velocity $W_{s}$, the sediment density $s$, the wave period $T_{w}$, and the orbital velocity at the bottom $U_{w}$, in Eq. 33. In order to keep the analogy with steady flows, an equivalent Froude number for waves $F_{r w}$ and the dimensionless settling velocity $W_{s *}$ proposed by Camenen et al. (2006) were introduced,

$$
F_{r w}=\frac{U_{w}}{\sqrt{g \delta}}
$$

where $\delta=\sqrt{\nu T_{w}}$ is the thickness of the viscous (Stokes) layer, $\nu$ the kinematic viscosity of the fluid, and:

$$
W_{s *}=\left[\frac{(s-1)^{2}}{(g \nu)}\right]^{1 / 3} W_{s}
$$


A study of the root-mean-square error using Eq. 33 with varying powers on $F_{r w}$ and $W_{s *}$ was carried out. Finally, by introducing the critical Shields parameter for upper plane bed regime $\theta_{c r, u r}$, such as $k_{s} / d_{50}=3$ when $\theta=\theta_{c r, u r}$ (in order to obtain an average of $k_{s} / d_{50}$ when $\theta<\theta_{c r, u r}$ approximately equal to 2$)$, the best fit was found for $a=0.6$, and $b=2.4$ with:

$$
\theta_{c r, u r}=0.115 \frac{F_{r w}^{1.20}}{W_{s *}^{0.40}(s-1)^{0.30}}
$$

Apart from the stronger effect of the relative density, Eq. 36 is quite similar to the equation obtained for the critical Shields parameter for the upper-regime under steady flows (i.e., $\theta_{c r, u r}=1.12 F_{r}{ }^{1.40} W_{s *}{ }^{-0.70}$ ). The present results appear to be not as sensitive as the steady flow results to the settling velocity but more sensitive to the sediment density.

\subsubsection{Comparison with experimental data}

Fig. 6 presents a comparison between effective roughness ratios $k_{s} / d_{50}$ obtained from the data and corresponding values computed with Eq. 33. It appears that Eq. 33 is not markedly affected by the different methods used to estimate the roughness height. Nevertheless, the effective roughness ratio was found to be proportional to the Shields parameter to the power 1.7, whereas the sheet flow layer thickness appeared to be proportional to the Shields parameter to the power 0.75 to 1.5 (see section 3.3.3). Thus, the hypothesis for the "sheet flow layer thickness" method that is $k_{s}=\delta_{s}$ seems to be accurate enough even if it corresponds to the maximum value for the proportionality with the Shields parameter. Indeed, if Eq. 33 is used to predict $\delta_{s}$ (assuming $k_{s}=\delta_{s}$ ) more them $95 \%$ of the data are correctly predicted within a factor 2 . Some data points derived using the "sediment transport" method are also overestimated by Eq. 33, but these data correspond to Shields parameter values close to the critical value for incipient motion where the method is expected to induce larger uncertainties.

Table 3 summarizes the predictions of equivalent roughness height for the different formulas within a factor of $2(P 2)$ and $5(P 5)$ of the measured values ("factor $x$ " means between $x$ times and $1 / x$ times the measured roughness height), as well as the mean value $(m f)$ and standard deviation $(s f)$ of the ratio $f=k_{s, \text { pred }} / k_{s, \text { expe }}$. The data set used for these calculations corresponds to all previously presented data apart from the data which clearly produce inaccurate results (that is data based on the "energy dissipation" method and the data from the "sediment transport" method where strong phase-lag were observed). It can be noted that there is a poor agreement between all previous formulas and the data within a factor of 2 (less than $50 \%$ of the data), and they sometimes yield an error of up to one order of magnitude. Thus, a logarithmic error index is proposed to establish a quantitative measure of the agreement between the formulas and the data. The term "Er $r_{\text {log }}$ " (logarithmic error index) is defined as,

$$
E r_{l o g}=\frac{100}{n} \sum_{1}^{n}\left|\log _{10}\left[\frac{\left(k_{s} / d_{50}\right)_{\text {pred }}}{\left(k_{s} / d_{50}\right)_{\text {expe }}}\right]\right|
$$




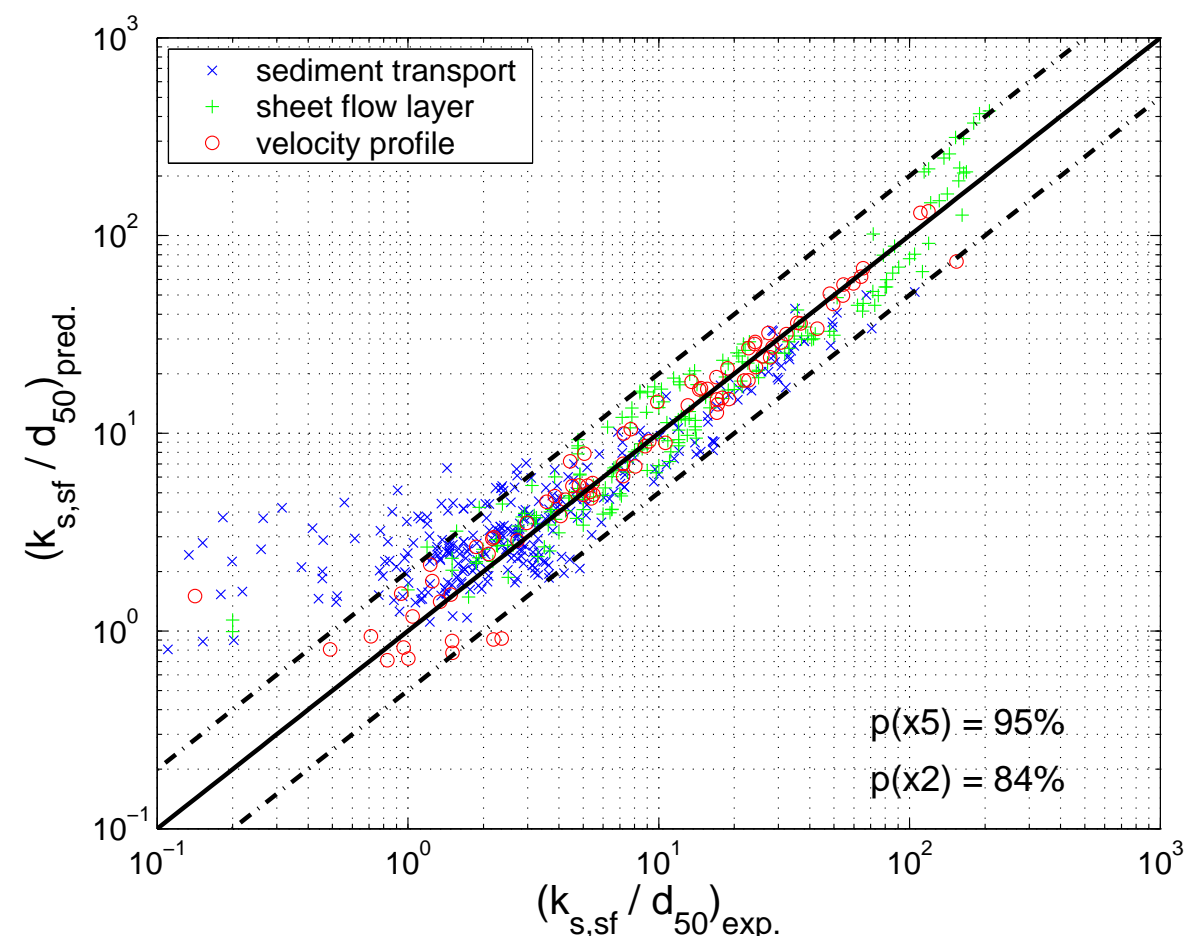

Figure 6: Comparison between effective roughness ratio obtained from the data and corresponding values computed with Eq. 33 (the bold line corresponds to a perfect agreement and the dashed lines correspond to prediction within a factor of 2).

Table 3: Prediction of equivalent roughness within a factor of 2 and 5 of the measured values together with a logarithmic error index for the studied formulas and all data.

\begin{tabular}{lccccc}
\hline Author(s) & $P 2$ & $P 5$ & $m f$ & $s f$ & $E r_{l o g}$ \\
\hline Grant \& Madsen & $2 \%$ & $10 \%$ & 0.40 & 0.24 & $338 \%$ \\
Wilson & $56 \%$ & $89 \%$ & -0.05 & 0.31 & $81 \%$ \\
Nielsen & $1 \%$ & $17 \%$ & 0.51 & 0.14 & $261 \%$ \\
Madsen et al. & $24 \%$ & $55 \%$ & 0.15 & 0.38 & $159 \%$ \\
Xu \& Wright & $35 \%$ & $76 \%$ & 0.27 & 0.27 & $118 \%$ \\
Ribberink & $49 \%$ & $89 \%$ & -0.16 & 0.30 & $84 \%$ \\
Eq. 33 & $86 \%$ & $95 \%$ & 0.05 & 0.19 & $48 \%$ \\
\hline
\end{tabular}

in which $n$ denotes the number of observations. An error of a factor 10 would thus lead to $E r_{l o g}=100$.

Large overestimations are observed for the Grant \& Madsen, Nielsen and Xu \& Wright formulas. However, it should be noted that the data set from Nielsen was not used for this comparison, which explains the poor results for this formula. The Wilson and Ribberink formulas tend to slightly underestimate the results for large Shields parameters $(\theta>1)$. However, for $\theta<1$, the Wilson formula underestimates the 
observation since it yields no minimum value. The Ribberink formula also produces underestimations since its minimum value $\left(k_{s}=d_{50}\right)$ is generally smaller than the observed values. Eq. 33 produces predictions that are much more accurate than previous relationships for most of the data sets. From Table 3, it is clear that Eq. 33 gives the best results for all measures of accuracy employed. Eq. 33 was however calibrated using the same data set it was tested against.

Fig. 7 displays the significant improvement of the roughness height predictions using Eq. 33 (bold lines) compared to formulas depending on the Shields parameter only (the Wilson formula is added as a reference, dashed lines). In order to construct these graphs, the data were divided into 8 groups for $0<\theta_{c r, u r}<0.20,0.20<\theta_{c r, u r}<0.40$, $0.40<\theta_{\text {cr,ur }}<0.60,0.60<\theta_{\text {cr }, u r}<0.80,0.80<\theta_{\text {cr, ur }}<1.00,1.00<\theta_{\text {cr, ur }}<1.50$, $1.50<\theta_{c r, u r}<2.00$, and $2.00<\theta_{c r, u r}<2.50$. Equation 33 was plotted using the mean value of $\theta_{c r, u r}$ for each group.
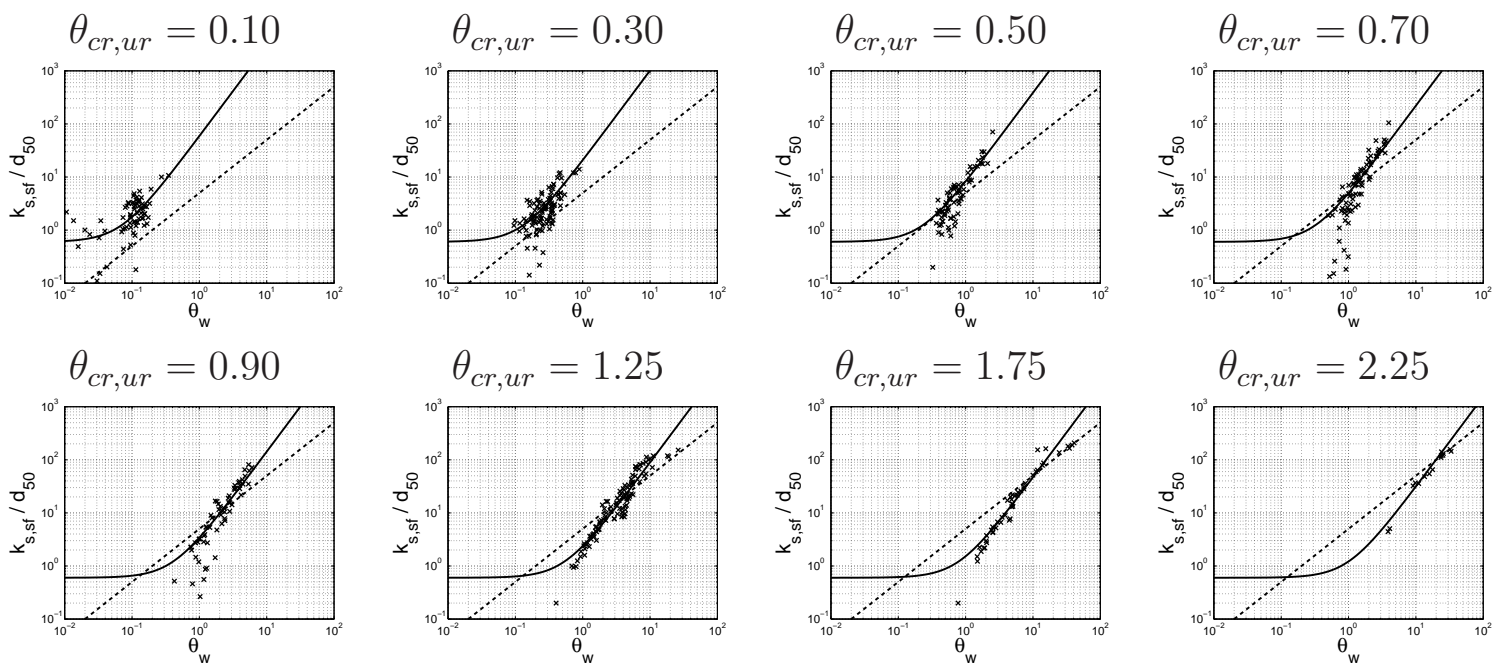

Figure 7: Dimensionless roughness height versus Shields parameter for different values on the critical Shields parameter for the upper regime (the bold lines correspond to Eq. 33 and the dashed lines to the Wilson formula, Eq. 3).

\subsubsection{Inception of sheet flow and upper-regime}

The inception of sheet flow corresponds to a situation where the wave ripples are disappearing, simultaneously as the energy is increasing (increasing wave orbital velocity). Thus, a relationship should exist between the inception of sheet flow and the inception of the upper regime defined in the previous section. Camenen \& Larson (2006) proposed a maximum value of the wave orbital velocity $U_{w, c r s f}$ for the inception of the sheet flow regime or wash-out of the wave ripples,

$$
U_{w, c r s f}=8.35 \sqrt{(s-1) g \sqrt{d_{50} \delta_{w}}}\left(1+r_{w}\right)
$$

where $r_{w}=\left(u_{w, \max }+u_{w, \min }\right) /\left(2 U_{w}\right)$ is the wave asymmetry. A critical Shields parameter $\theta_{c r, s f}$ for the inception of sheet-flow may be obtained from Eq. 38 adding a 
coefficient which is a function of the dimensionless grain size $d_{*}=\sqrt[3]{(s-1) g / \nu^{2}} d_{50}$ (cf. Hanson \& Camenen, 2007):

$$
\theta_{c r, s f}=10 d_{*}^{-3 / 4} \sqrt{\frac{d_{50}}{\delta_{w}}}\left(1+r_{w}\right)^{2}
$$

The Van Rijn formula (1993) which is only a function of $d_{*}\left(\theta_{c r, s f}=26 \theta_{c r}\right)$ yields very similar results though it is not a function of the wave period.

In Fig. 8 are the different equations for the critical Shields parameters for the inception of sheet flow and upper regime plotted versus the dimensionless grain size. As $\theta_{c r, u r}$ is a function of the wave orbital velocity, it has been plotted for four different values of $U_{w}$ from 0.25 to $2 \mathrm{~m} / \mathrm{s}$ (with $T_{w}=6 \mathrm{~s}$ and $r_{w}=0$ ). It appears that $\theta_{c r, u r}$ yields a similar behavior as $\theta_{c r, s f}$ with respect to the grain size (decreasing function of $d_{*}$ ). Eqs. 36 and 39 also have a similar sensitivity to the wave period (or $\delta_{w}$ ). However, Eq. 36 for $\theta_{c r, u r}$ differs from the two other relationships for $\theta_{c r, s f}$ as it is also sensitive to the wave orbital velocity and then yields much smaller value when $U_{w}<0.5 \mathrm{~m} / \mathrm{s}$. By definition, the lower plane bed regime, where the equivalent roughness height may be approximate as the grain-related roughness height (i.e. $k_{s} \approx 2 d_{50}$ ), is differentiated from the upper plane bed regime for which $k_{s}>2 d_{50}$. Thus the sheet flow regime is a specific case of the upper plane bed regime (for the sheet flow regime, $k_{s}$ was always observed to be much larger than $2 d_{50}$ ) and $\theta_{c r, u r} \leq \theta_{c r, s f}$.

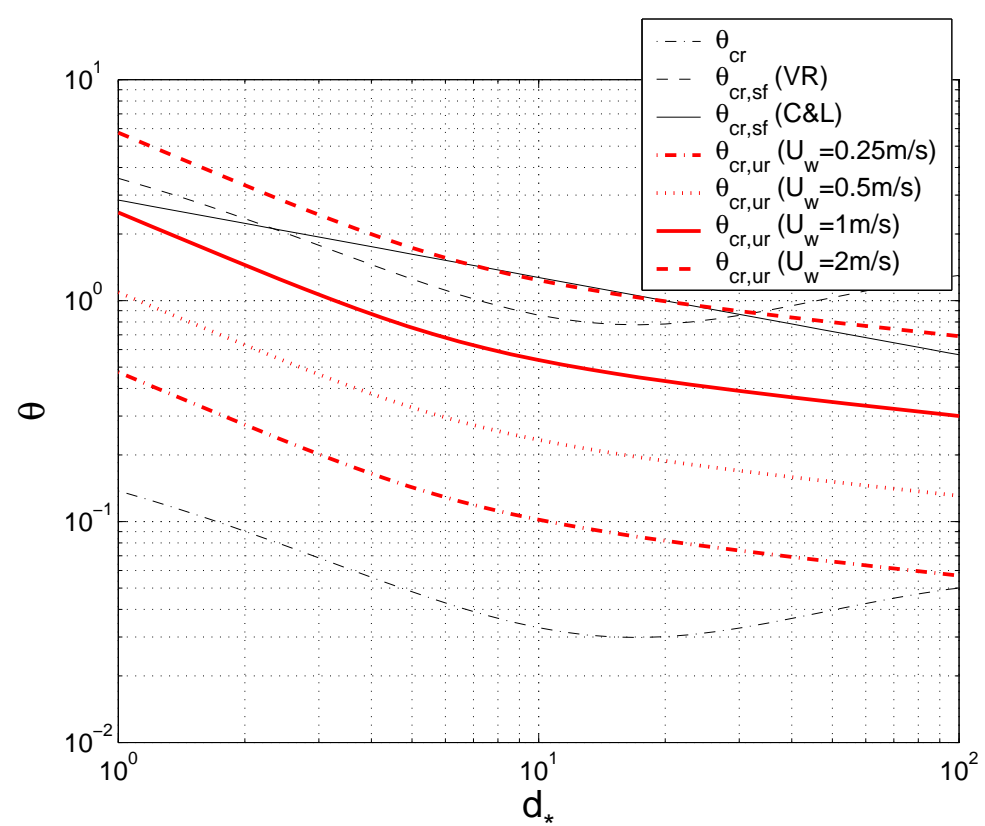

Figure 8: Comparison between the critical Shields parameter for the upper regime and critical Shields parameters for the inception of sheet flow (VR: Van Rijn, 1993; C\&L: Camenen \& Larson,). 


\section{Conclusion}

In the present study, data from various sources were compiled and analyzed to determine the roughness height for plane-bed regime under oscillatory flow. Based on this analysis, the following conclusions were drawn:

- Several methods were used and proposed to estimate the roughness height. The "velocity profile", "momentum equation" and "sediment transport" methods appear to give a fairly consistent estimation of $k_{s}$. On the other hand, the "energy dissipation" method induces larger values on the roughness height. However, this method was not validated against any other method.

- The sheet flow layer thickness was found to be a function of the total Shields parameter. The ratio between the sheet flow layer thickness and erosion depth varies from 3 for medium shear stresses to 1 for large shear stresses. The assumption that $k_{s}=\delta_{s}$ appeared to be correct.

- Flow resistance for plane beds under oscillatory flow can be expressed in terms of the ratio of Nikuradse's equivalent sand roughness to the grain diameter, $k_{s} / d_{50}$, given as function of the Shields parameter based on the total shear stress, and a critical Shields parameter, according to Eq. 33. $\theta_{c r, u r}$ defines the limit between the lower- regime where $k_{s} / d_{50}$ may be consider as constant and the upper-regime where $k_{s} / d_{50}$ is a function of the Shields parameter.

- Similar results for the effective roughness height were observed for the oscillatory flow as for the steady current ( $c f$. Camenen et al., 2006), i.e., $k_{s} / d_{50}$ is proportional to the total Shields parameter to the power 1.7 as soon as $\theta_{c r, u r}$ is reached.

- The critical Shields parameter for the upper regime $\theta_{c r, u r}$ was found to be a function of the settling velocity, the sediment density, and a wave-equivalent Froude number. This value is strongly related to the critical Shields parameter for inception of sheet flow, but may yield also much lower values. As a result, it appears that the roughness height may increase as soon as sediment transport occurs. Also, the sheet-flow regime was found to be a specific case of the upper plane bed regime.

- The proposed relationship (Eqs. 33 and 36) yields the best results among the studied formulas. Also these equations may also be used to estimate the sheetflow layer thickness as soon as the sheet-flow regime is reached.

- A relationship between the roughness height and the total Shields parameter makes iterative computations necessary in practical applications. Such a method could imply large discrepancies in the results compared to the direct fitting using measured data, and thus needs to be improved.

- Some other effects may influence the roughness height and friction coefficient. Myrhaug and Holmedal (2005) argued that the boundary layer streaming may 
affect the bed shear stress for laminar (with relatively high Reynolds numbers) and smooth turbulent flows (with relatively low Reynolds numbers). Acceleration does affect the instantaneous shear stress (and roughness height) by inducing a phase lead and an increase/decrease of the shear stress for accelerating/decelerating flows. Thus, the instantaneous roughness height (and friction coefficient) may fluctuate around its mean value. Although these fluctuations may induce some onshore-directed sediment transport (Nielsen, 2002; Camenen and Larson, 2007a), the purpose of this study was to better identify the mean value on the roughness.

\section{Acknowledgments}

This work was in part (B.C., M.L., and A.B.) conducted under the Inlet Modeling System Work Unit of the Coastal Inlets Research Program, U.S. Army Corps of Engineers, and in part (B.C.) under the Humor programme supported by the European Community and the Japanese Society for the Promotion of Sciences. The reviewers are also thanked for their useful comments.

\section{References}

Ahilan, R. \& Sleath, J. (1987), 'Sediment transport in oscillatory flow over flat beds', J. Hydraulic Eng. 113(3), 308-322.

Ahmed, A. \& Sato, S. (2003), 'A sheet-flow transport model for asymmetric oscillatory flow, part I: uniform grain size sediments', Coastal Eng. J. 45(3), 321-337.

Asano, T. (1992), Observations of granular-fluid mixture under an oscillatory sheet flow, in 'Proc. 23rd Int. Conf. Coastal Eng.', ASCE, Venice, Italy, pp. 1896-1909.

Asano, T. (1995), 'Sediment transport under sheet-flow conditions', J. Waterways, Port, Coastal \& Ocean Eng. 121(5), 239-246.

Bayram, A., Camenen, B. \& Larson, M. (2003), Equivalent roughness under sheet flow conditions, in 'Proc. Coastal Sediments'03', ASCE, Clearwater Beach, Florida, USA. (CD ROM).

Bayram, A., Larson, M., Miller, H. \& Kraus, N. (2001), 'Cross-shore distribution of longshore sediment transport: comparison between predictive formulas and field measurements', Coastal Eng. 44(C5), 79-99.

Camenen, B., Bayram, A. \& Larson, M. (2006), 'Equivalent roughness height for plane bed under steady flow', J. Hydraulic Eng. 132(11), 1146-1158.

Camenen, B. \& Larson, M. (2005), 'A bedload sediment transport formula for the nearshore', Estuarine, Coastal \& Shelf Science 63, 249-260. 
Camenen, B. \& Larson, M. (2006), 'Phase-lag effects in sheet flow transport', Coastal Eng. 53, 531-542.

Camenen, B. \& Larson, M. (2007a), A total load formula for the nearshore, in 'Proc. Coastal Sediments'07', ASCE, New Orleans, Louisiana, USA.

Camenen, B. \& Larson, M. (2007b), A unified sediment transport formulation for coastal inlet application, Technical Report CR-07-1, ERDC/CHL.

Carstens, M., Neilson, F. \& Altinbilek, H. (1969), Bedforms generated in the laboratory under an oscillatory flow, Technical Report 28, CERC Technical Memorandum.

Dibajnia, M. \& Watanabe, A. (1992), Sheet flow under nonlinear waves and currents, in 'Proc. 23rd Int. Conf. Coastal Eng.', ASCE, Venice, Italy, pp. 2015-2029.

Dick, J. \& Sleath, J. (1991), 'Velocities and concentrations in oscillatory flow over beds of sediment', J. Fluid Mechanics 233, 165-196.

Dohmen-Janssen, C. \& Hanes, D. (2002), 'Sheet flow dynamics under monochromatic nonbreaking waves', J. Geophysical Res. 107(C10), 13:1-13:21.

Dohmen-Janssen, C., Hassan, W. \& Ribberink, J. (2001), 'Mobile-bed effects in oscillatory sheet-flow', J. Geophysical Res. 106(C11), 27103-27115.

Dohmen-Janssen, M. (1999), Grain size influence on sediment transport in oscillatory sheet flow, phase-lags and mobile-bed effects, PhD thesis, Delft University of Technology, The Netherlands. ISBN 90-9012929-4.

Grant, W. \& Madsen, O. (1982), 'Movable bed roughness in unsteady oscillatory flow', J. Geophysical Res. 87(C1), 469-481.

Grant, W. \& Madsen, O. (1986), The continental shelf bottom boundary layer, in M. V. Dyke, ed., 'Annual Review of Fluid Mechanics', Vol. 18, pp. 265-305.

Guy, H., Simmons, D. \& Richardson, E. (1966), Summary of alluvial channel data from flume experiment 1956-1961, Technical Report 462-I, U.S. Geological Survey, Professional Paper, Washigton D.C. 96 pp.

Hanson, H. \& Camenen, B. (2007), Closed form solution for threshold velocity for initiation of sediment motion under waves, in 'Proc. Coastal Sediments'07', ASCE, New Orleans, Louisiana, USA, pp. 15-28.

Horikawa, K., Watanabe, A. \& Katori, S. (1982), Sediment transport under sheet flow conditions, in 'Proc. 18th Int. Conf. Coastal Eng.', ASCE, Cape Town, South Africa, pp. 1335-1352.

Jonsson, I. (1966), Wave boundary layers and friction factors, in 'Proc. 10th Int. Conf. Coastal Eng.', ASCE, Tokyo, Japan, pp. 127-148. 
Jonsson, I. (1980), 'A new approach to oscillatory rough turbulent boundary layers', Ocean Eng. 7, 109-152.

Kamphuis, J. (1974), 'Determination of sand roughness for fixed beds', J. Hydraulic Res. 12(2), 193-203.

King, D. (1991), Studies in oscillatory flow bedload sediment transport, PhD thesis, University of California, San Diego.

Li, L. \& Sawamoto, M. (1995), 'Experiments on sediment transport in sheet-flow regime under oscillatory flow', Coastal Eng. J. 38(2), 157-178.

Lofquist, K. (1986), Drag on naturally rippled beds under oscillatory flows, Miscellaneous Paper CERC-86-13, Coastal Engineering Research Center, U.S. Army Corps of Engineers.

Madsen, O. (1993), Sediment transport outside the surf zone, unpublished technical report, Waterways Experiment Station, U.S. Army Corps of Engineer, Vicksburg, Mississippi, USA.

Meyer-Peter, E. \& Müller, R. (1948), Formulas for bed-load transport, in '2nd Meeting of the International Association for Hydraulic Structures Research', IAHR, Stockholm, Sweden, pp. 39-64.

Myrhaug, D. \& Holmedal, L. (2005), 'Bottom friction caused by boundary layer streaming beneath random waves for laminar and smooth turbulent flow', Ocean Eng. 32(2), 195-22.

Nielsen, P. (1992), Coastal bottom boundary layers and sediment transport, Vol. 4 of Advanced Series on Ocean Engineering, World Scientific Publication, Singapore.

Nielsen, P. (2002), 'Shear stress and sediment transport calculations for swash zone modeling', Coastal Eng. 45(1), 53-60.

Nnadi, F. \& Wilson, K. (1992), 'Motion of contact-load particules at high shear stress', J. Hydraulic Eng. 118(12), 1670-1684.

O'Donoghue, T. \& Wright, S. (2004), 'Flow tunnel measurements of velocities and sand flux inoscillatory sheet flow for well-sorted and graded sands', Coastal Eng. $51,1163-1184$.

Pugh, F. \& Wilson, K. (1999), 'Velocity and concentration distributions in sheet flow above plane beds', J. Hydraulic Eng. 125(2), 117-125.

Ribberink, J. (1998), 'Bed-load transport for steady flows and unsteady oscillatory flows', Coastal Eng. 34, 52-82.

Ribberink, J. \& Al Salem, A. (1994), 'Sediment transport in oscillatory boundary layers in cases of rippled beds and sheet flow', J. Geophysical Res. 99(C6), 707-727. 
Ribberink, J. \& Chen, Z. (1993), Sediment transport of fine sand under asymmetric oscillatory flow, Delft Hydraulics, Report H840, part VII, The Netherlands.

Sawamoto, M. \& Yamashita, T. (1986), 'Sediment transport rate due to wave action', J. Hydroscience \& Hydraulic Eng. 4(1), 1-15.

Sleath, J. (1978), 'Measurements of bed load in oscillatory flow', J. Waterways Harbors Division 10(4), 291-307.

Sleath, J. (1987), 'Turbulent oscillatory flow over rough beds', J. Fluid Mechanics 182, 369-409.

Soulsby, R. (1997), Dynamics of marine sands, a manual for practical applications, Thomas Telford, London, UK. ISBN 0-7277-2584.

Sumer, B., Kozakievicz, A., Fredsœe, J. \& Deigaard, R. (1996), 'Velocity and concentration profiles in the sheet-flow layer of movable bed', J. Hydraulic Eng. 122(10), 549-558.

Swart, D. (1974), Offshore sediment transport and equilibrium beach profiles, Technical report, Delft Hydraulics Lab. Publ., Delft, The Netherlands.

Van Rijn, L. (1993), Principles of sediment transport in rivers, estuaries and coastal seas, Aqua Publications, The Netherlands.

Watanabe, A. \& Isobe, M. (1990), Sand transport rate under wave-current action, in 'Proc. 22nd Int. Conf. Coastal Eng.', ASCE, Delft, the Netherlands, pp. 24952506.

Wijetunge, J. \& Sleath, J. (1998), 'Effects of sediment transport on bed friction and turbulence', J. Waterways, Port, Coastal \& Ocean Eng. 124, 172-178.

Wilson, K. (1966), 'Bed-load transport at high shear stress', J. Hydraulic Division 92(11), 49-59.

Wilson, K. (1987), 'Analysis of bed-load motion at high shear stress', J. Hydraulic Eng. 113(1), 97-103.

Wilson, K. (1989), 'Friction of wave induced sheet flow', Coastal Eng. 12, 371-379.

Wilson, K. \& Pugh, F. (1989), 'Dispersive-force basis for concentration profiles', J. Hydraulic Eng. 114(7), 806-810.

Xu , J. \& Wright, L. (1993), 'Tests of bed roughness models using field data from the middle Atlantic Bight', Continental Shelf Res. 15(11-12), 1409-1434.

Yalin, M. (1977), Mechanics of Sediment Transport, Pergamon Press, Oxford. 2nd edition.

Zala Flores, N. \& Sleath, J. (1998), 'Mobile layer in oscillatory sheet flow', J. Geophysical Res. 106(C6), 12783-12793. 


\section{Notation}

The following symbols and subscripts are used in this paper:

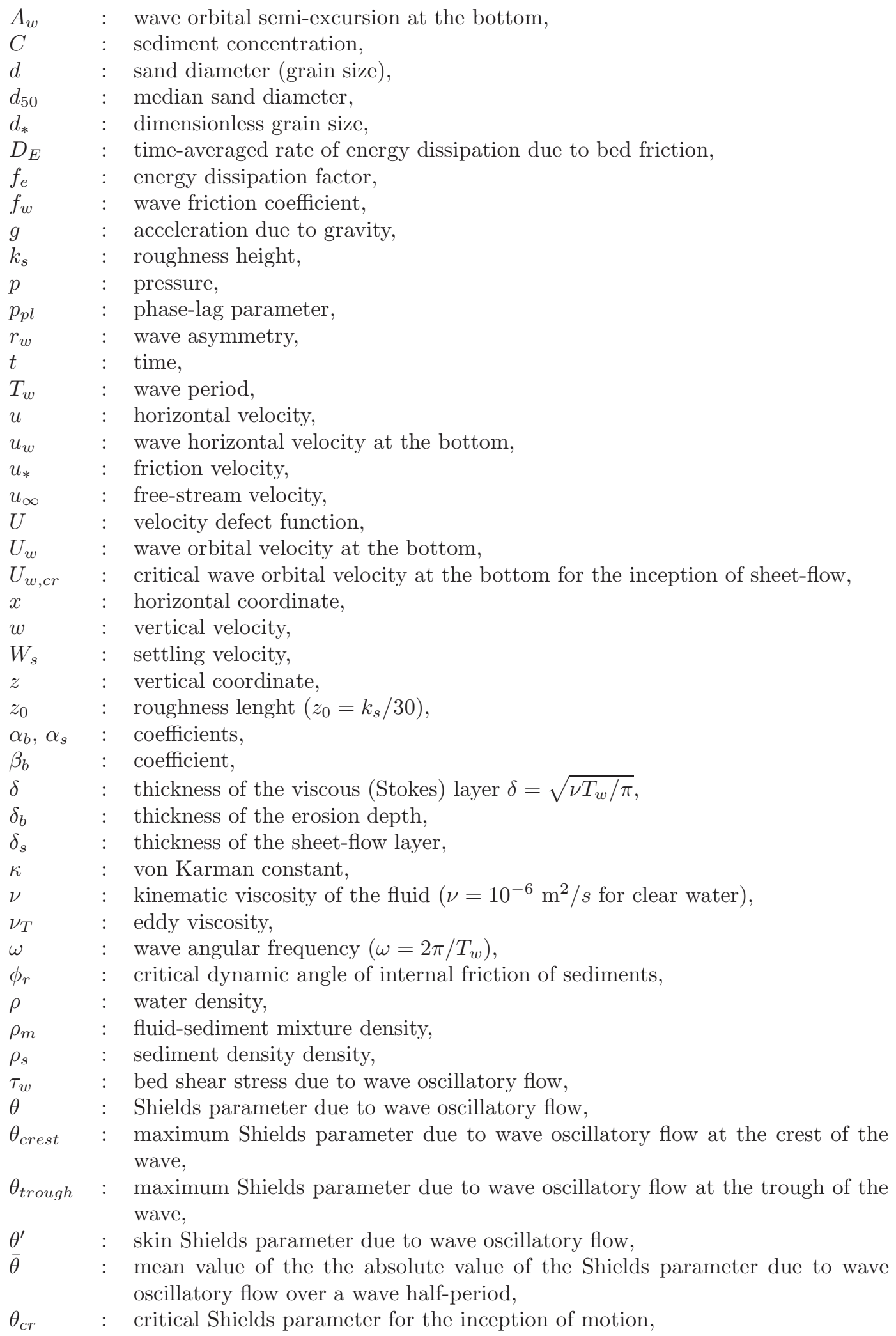


$\theta_{c r, u r}:$ critical Shields parameter for the inception of upper regime,

$\theta_{c r, s f}:$ critical Shields parameter for the inception of sheet flow, 